\title{
Cocaine Hijacks $\sigma 1$ Receptor to Initiate Induction of Activated Leukocyte Cell Adhesion Molecule: Implication for Increased Monocyte Adhesion and Migration in the CNS
}

\author{
Honghong Yao, ${ }^{1}$ Keejun Kim, ${ }^{2}$ Ming Duan, ${ }^{1}$ Teruo Hayashi, ${ }^{3}$ Minglei Guo, ${ }^{4}$ Susan Morgello, ${ }^{5}$ Alexander Prat, ${ }^{6}$ \\ John Wang, ${ }^{4}$ Tsung-Ping Su, ${ }^{3}$ and Shilpa Buch ${ }^{1}$ \\ ${ }^{1}$ Department of Pharmacology and Experimental Neuroscience, University of Nebraska Medical Center, Omaha, Nebraska 68198, ${ }^{2}$ Department of \\ Microbiology, Molecular Genetics, and Immunology, University of Kansas Medical Center, Kansas City, Kansas 66160, ${ }^{3}$ Cellular Pathobiology Section, \\ Cellular Neurobiology Research Branch, Intramural Research Program, National Institute on Drug Abuse-National Institutes of Health, Baltimore, \\ Maryland 21224, ${ }^{4}$ Department of Basic Medical Science, University of Missouri-Kansas City School of Medicine, Kansas City, Missouri 64108, ${ }^{5}$ National \\ NeuroAIDS Tissue Consortium, Mount Sinai Hospital, New York, New York 10029, and ${ }^{6}$ Neuroimmunology Research Laboratory, Center for Excellence in \\ Neuromics, Centre Hospitalier de l'Université de Montréal-Notre-Dame Hospital, Université de Montréal, Montréal, Québec H2L 4M1, Canada
}

Human immunodeficiency virus (HIV)-associated increase in monocyte adhesion and trafficking is exacerbated by cocaine abuse. The underlying mechanisms involve cocaine-mediated upregulation of adhesion molecules with subsequent disruption of the blood-brain barrier (BBB). Recently, a novel activated leukocyte cell adhesion molecule (ALCAM) has been implicated in leukocyte transmigration across the endothelium. We now show that upregulation of ALCAM in the brain endothelium seen in $\mathrm{HIV}^{+} / \mathrm{cocaine}^{\mathrm{drug}}$ abusers paralleled increased CD68 immunostaining compared with $\mathrm{HIV}^{+} /$no cocaine or uninfected controls, suggesting the important role of ALCAM in promoting leukocyte infiltration across the BBB. Furthermore, ALCAM expression was increased in cocaine-treated mice with concomitant increase in monocyte adhesion and transmigration in vivo, which was ameliorated by pretreating with the neutralizing antibody to ALCAM, lending additional support to the role of ALCAM. This new concept was further confirmed by in vitro experiments. Cocaine-mediated induction of ALCAM in human brain microvascular endothelial cells through the translocation of $\sigma$ receptor to the plasma membrane, followed by phosphorylation of PDGF- $\beta$ (platelet-derived growth factor- $\beta$ ) receptor. Downstream activation of mitogen-activated protein kinases, Akt, and NF- $\kappa \mathrm{B}$ (nuclear factor $-\kappa \mathrm{B}$ ) pathways resulted in induced expression of ALCAM. Functional implication of upregulated ALCAM was confirmed using cell adhesion and transmigration assays. Neutralizing antibody to ALCAM ameliorated this effect. Together, these findings implicate cocaine-mediated induction of ALCAM as a mediator of increased monocyte adhesion/transmigration into the CNS.

\section{Introduction}

Although the advent of antiretroviral therapy has decreased the incidence of human immunodeficiency virus (HIV)-associated neurocognitive disorders (HAND), its prevalence is actually on a rise. Drug abuse has been implicated as a contributing risk factor for HIV-1 infection. Intriguingly, cocaine has been shown to facilitate transmigration of inflammatory leukocytes into the brain (Fiala et al., 1998, 2005). Viral entry into the CNS is mediated, in part, by the transmigration of HIV-infected monocytes into the brain. Leukocyte transmigration is a dynamic, multistep process

\footnotetext{
Received Oct. 26, 2010; revised Jan. 15, 2011; accepted Feb. 17, 2011.

This work was supported by National Institutes of Health Grants MH-068212, DA020392, DA023397, DA024442 (S.B.), and DA030285 (H.Y.), and by Clinical Research Center of the Mount Sinai School of Medicine Grant M01-RR00071 (S.M.).

The authors declare no competing financial interests.

Correspondence should be addressed to Dr. Shilpa Buch, Department of Pharmacology and Experimental Neuroscience, 985880 Nebraska Medical Center (DRC 8011), University of Nebraska Medical Center, Omaha, NE 681985880. E-mail: sbuch@unmc.edu.

DOI:10.1523/JNEUROSCI.5618-10.2011

Copyright $\odot 2011$ the authors $\quad 0270-6474 / 11 / 315942-14 \$ 15.00 / 0$
}

involving initial "rolling" of cells on the vessel endothelium in response to inflammatory mediators and subsequent adhesion and diapedesis across the systemic vasculature (Carlos and Harlan, 1994). Interaction of endothelial adhesion molecules with their cognate ligands on monocytes is critical for this process.

Upregulation of adhesion molecules such as ICAM-1/ VCAM-1 is pivotal for development of inflammatory responses. Recently, discovery of a novel activated leukocyte cell adhesion molecule (ALCAM/CD166) has been shown to play important roles in the migration of THP-1 monocytes (Masedunskas et al., 2006) and regulatory T-cells (Nummer et al., 2007). ALCAM also participates in the migration of leukocytes from the periphery into the CNS in multiple sclerosis (MS) and experimental autoimmune encephalomyelitis (EAE) (Cayrol et al., 2008). Interactions between ALCAM expressed on endothelial cells and leukocytes may thus be critical for leukocyte transmigration across the endothelium (Swart, 2002; Masedunskas et al., 2006).

Aberrant expression of adhesion molecules has been implicated as an early step in the development of neurological disease associated with HIV infection and cocaine abuse. Cocaine abuse 
is known to exacerbate HIV-associated neuroinflammation through multiple mechanisms involving upregulation of adhesion molecules (Gan et al., 1999) and potentiation of neurotoxicity (Bagasra and Pomerantz, 1993; Koutsilieri et al., 1997). Although cocaine-mediated increase in ICAM-1 and VCAM-1 has been demonstrated in brain microvascular endothelial cells (Gan et al., 1999), its role in regulating ALCAM remains elusive.

The present study was aimed at exploring the molecular mechanisms by which cocaine mediates the induction of ALCAM in human brain microvascular endothelial cells (HBMECs). Understanding the regulation of ALCAM expression by cocaine may provide insights into the development of therapeutic targets aimed at blocking neuroinflammation.

\section{Materials and Methods}

Reagents. $\sigma$ receptor antagonist $N^{\prime}$-[2-(3,4-dichlorophenyl)ethyl]- $N, N, N^{\prime}$ trimethylethane-1,2-diamine (BD1047) and I $\kappa$ B kinase-2 inhibitor 4-amino- $\left[2^{\prime}, 3^{\prime}\right.$-bithiophene $]$-5-carboxamide (SC514) were purchased from Sigma-Aldrich. 4-[(4-Methylpiperazin-1-yl)methyl]-N-[4-methyl-3-[(4pyridin-3-ylpyrimidin-2-yl)amino]phenyl] benzamide (STI-571), an inhibitor of platelet-derived growth factor (PDGF) receptor tyrosine kinase, was obtained from Novartis. The specific mitogen-activated protein kinase (MAPK) kinase 1/2 (MEK1/2) inhibitor 1,4-diamino-2,3-dicyano-1,4bis(2-aminophenylthio)butadiene (U0126), c-Jun N-terminal kinase (JNK) inhibitor $2 H$-dibenzo $[c d, g]$ indazol-6-one (SP600125), p38 inhibitor 4-[4(4-fluorophenyl)-2-(4-methylsulfinylphenyl)- $1 H$-imidazol-5-yl]pyridine (SB203580), Src kinase inhibitor (4-amino-5-(4-chlorophenyl)-7-(dimethylethyl)pyrazolo $[3,4-d]$ pyrimidine (PP2) and its inactive ortholog 1-phenyl$1 H$-pyrazolo[3,4-d]pyrimidin-4-amine (PP3), phosphatidylinositol 3-kinase (PI3K) inhibitor 2-morpholin-4-yl-8-phenylchromen-4-one (LY294002) were purchased from Calbiochem. The concentrations of these inhibitors were based on the concentration curve study and our previous reports (Yao et al., 2010). Adenovirus vectors expressing either the wild-type (WT) or dominant-negative (DN) forms of Akt were obtained from Dr. K. Walsh (Tufts University School of Medicine, Boston, MA). Recombinant adenovirus vectors coexpressing either green fluorescent protein (GFP) and full-length RelA (RelAFL), or mutant were provided by Dr. S. Maggirwar (University of Rochester Medical Center, Rochester, NY). HBMECs were pretreated with pharmacological inhibitors (20 $\mu \mathrm{M}$ BD1047; $1 \mu \mathrm{M}$ STI-571; $10 \mu \mathrm{M}$ PP2; $1 \mu \mathrm{M}$ PP3; $20 \mu \mathrm{M}$ U0126; $20 \mu \mathrm{M}$ SP600125; $20 \mu \mathrm{M}$ SB203580; 20 $\mu \mathrm{M}$ LY294002; $5 \mu \mathrm{M}$ SC514) for $1 \mathrm{~h}$ followed by cocaine exposure.

Animals. C57BL/6N male mice and the nude mice were purchased from Charles River Laboratories. All of the animals were housed under conditions of constant temperature and humidity on a $12 \mathrm{~h}$ light/dark cycle, with lights on at 7:00 A.M. Food and water were available ad libitum. For systemic inflammation, mice were injected with lipopolysaccharide (LPS) (Escherichia coli O111:B4) intraperitoneally at $10 \mathrm{mg} / \mathrm{kg}$. All animal procedures were performed according to the protocols approved by the Institutional Animal Care and Use Committee of the University of Nebraska Medical Center.

Cell culture. Primary HBMECs obtained from Dr. Monique Stins (The Johns Hopkins University, Baltimore, MD) were cultured in RPMI 1640 medium containing $10 \%$ heat-inactivated fetal bovine serum, $10 \% \mathrm{Nu}-$ Serum, $2 \mathrm{~mm}$ glutamine, $1 \mathrm{~mm}$ pyruvate, penicillin $(100 \mathrm{U} / \mathrm{ml})$, streptomycin $(100 \mu \mathrm{g} / \mathrm{ml})$, essential amino acids, and vitamins. Purified HBMECs were positive for endothelial makers DiI-AcLDL (left panel), ZO-1 (middle panel), and $\beta$-catenin (right panel) and were found to be $>99 \%$ pure after exclusion of staining for nonendothelial cell type markers (GFAP, smooth muscle actin, cytokeratin, and macrophage antigens). Early passages P3-P7 were used in this study.

Lipid raft isolation and analysis. Lipid raft were isolated from confluent HBMECs treated with cocaine according to the previous study (Cayrol et al., 2008). Briefly, lysates were mixed with $1 \mathrm{ml}$ of $85 \%$ (w/v) sucrose, were overlaid with $35 \%$ sucrose and $5 \%$ sucrose $(5 \mathrm{ml}$ each), and were centrifuged for $24 \mathrm{~h}$ at $39,000 \mathrm{rpm}$ (Beckman SW 4 rotor) and $4^{\circ} \mathrm{C}$. Twelve $1 \mathrm{ml}$ fractions were collected, from the top to bottom. The concentration of cholesterol and protein in each fraction was analyzed with a cholesterol assay kit (Invitrogen) and a BCA protein assay kit (Pierce).
Reverse transcription and real-time PCR. The quantitative PCR primers for human ALCAM were obtained from SABiosciences (catalog \#PPH00622A-200). Total RNA was extracted with Trizol reagent (Invitrogen) according to the manufacturer's instructions and our previous report (Yao et al., 2010).

Flow cytometry. HBMECs treated with cocaine were collected in cold PBS and EDTA (5 mM) followed by incubation with anti-ALCAM (3A6; 1:100), anti-ICAM-1 (HA58; 1:1000), and anti-VCAM-1 (51-10C9; $1: 100)$. LSR II (BD Biosciences) was used for fluorescence acquisition, and data were analyzed with FACSDiva software (BD Biosciences).

Short interfering RNA transfection. HBMECs were transfected with short interfering RNA (siRNA) for $\sigma 1 \mathrm{R}$ and PDGF- $\beta$ R that were obtained from Dharmacon and used according to the manufacturer's instructions. The knockdown efficiency of siRNAs was determined after $2 \mathrm{~d}$ of transfection by Western blotting.

In vitro binding assay. The intracellular domain of human PDGF- $\beta \mathrm{R}$ (557-end) with an N-terminal glutathione-S-transferase (GST) tag (GST-PDGF- $\beta$ R) was expressed and purified via a baculovirus/Sf9 insect cell expression system. To express $\sigma 1 \mathrm{R}$ proteins, HEK293T cells were transiently transfected $(48 \mathrm{~h})$ with a mammalian TrueORF expression plasmid $(5 \mu \mathrm{g})$ encoding full-length human $\sigma 1 \mathrm{R} \mathrm{cDNA}$ (Origene) followed by lysis in modified radioimmunoprecipitation assay (RIPA) buffer and centrifugation. The quantity of $\sigma 1 \mathrm{R}$ was determined by immunoblots using a rabbit anti- $\sigma 1 \mathrm{R}$ antibody that stably expressed high levels of full-length $\sigma 1 \mathrm{R}$. Binding reactions (buffer: $200 \mathrm{~mm} \mathrm{NaCl}, 0.2 \%$ Triton X-100, $0.1 \mathrm{mg} / \mathrm{ml} \mathrm{BSA}$, and $50 \mathrm{~mm}$ Tris, $\mathrm{pH} 7.5)$ were initiated by adding GST or GST-PDGF- $\beta \mathrm{R}(2 \mu \mathrm{g})$ and $\sigma 1 \mathrm{R}(2 \mu \mathrm{g})$ proteins and were maintained at $4^{\circ} \mathrm{C}(2-3 \mathrm{~h})$. GST-fusion proteins were precipitated using $100 \mu \mathrm{l}$ of $10 \%$ glutathione Sepharose and the precipitate washed thrice with binding buffer. Bound proteins were eluted with $2 \times$ SDS loading buffer, resolved by SDS-PAGE, and immunoblotted with an anti- $\sigma 1 \mathrm{R}$ antibody.

Fluorescence resonance energy transfer. $\mathrm{CHO}$ cells were transfected for $6 \mathrm{~h}$ with Lipofectamine 2000 to express PDGF $\beta$ R-GFP and $\sigma 1 \mathrm{R}-\mathrm{RFP}$. Transfected cells were seeded on poly-D-lysine-coated round coverslips. One day after transfection, cells were cultured in serum-free medium for $4 \mathrm{~h}$ and subjected to fluorescence resonance energy transfer (FRET) analysis. Briefly, three images were acquired with the PerkinElmer UltraView confocal system: a donor image (excite with a green laser, emit with a GFP filter), an acceptor image [excite with a red laser, emit with a red fluorescent protein (RFP) filter], and a FRET image (excite with a green laser, emit with a RFP filter). Bleed-through constants and cross talk of each dye were calculated with the Velocity software (PerkinElmer) based on fluorescence intensities obtained from samples expressing only PDGF $\beta$ R-EGFP or $\sigma 1 \mathrm{R}$-RFP. The "corrected" FRET was calculated from the net FRET according to those constants and further normalized to the intensity of the donor fluorophore (i.e., normalized FRET). The normalized FRET image was presented with a rainbow color scale.

PDGF antibody array. PDGF antibody array was performed according to the manufacturer's instructions (Full Moon Biosystems). Briefly, confluent cultures of HBMECs treated with cocaine $(10 \mu \mathrm{M})$ or untreated were used for isolation of lysates. Total proteins in the lysates were biotinylated and incubated with the antibody-coated slides, followed by washes and incubation with Cy3-streptavidin. The slides were scanned on Axon GenePix Array Scanner (Molecular Devices) to detect bound biotinylated proteins. The fold change was calculated using the ratio of phosphorylated PDGF- $\beta$ R in the presence versus absence of cocaine. The antibody array analysis was repeated twice independently.

Chromatin immunoprecipitation assay. Chromatin immunoprecipitation (ChIP) assay was performed according to the manufacturer's instructions (Millipore). Purified DNA was subjected to PCR to identify the promoter region containing nuclear factor- $\kappa \mathrm{B}$ (NF- $\kappa \mathrm{B})$ binding site "GGA GGG TCC G." The sequence of the primers used to identify the ALCAM promoter bound by transcription factor NF- $\kappa$ B was as follows: sense, $5^{\prime}$-GAACGGACCAAGACGGACTT-3'; antisense, 5'-GCCCGGTACCAACAGAAA-3'.

Monocyte isolation, human immunodeficiency virus 1 infection, monocyte adhesion and transmigration. Monocytes were obtained from HIV1/HIV-2/hepatitis B seronegative donor leukopacks, and separated by countercurrent centrifugal elutriation as previously described (Gendel- 
A
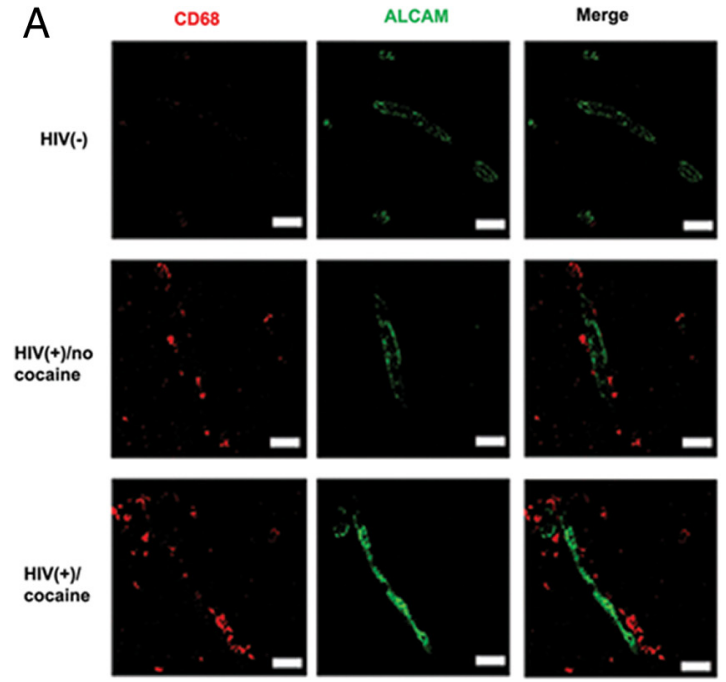

B
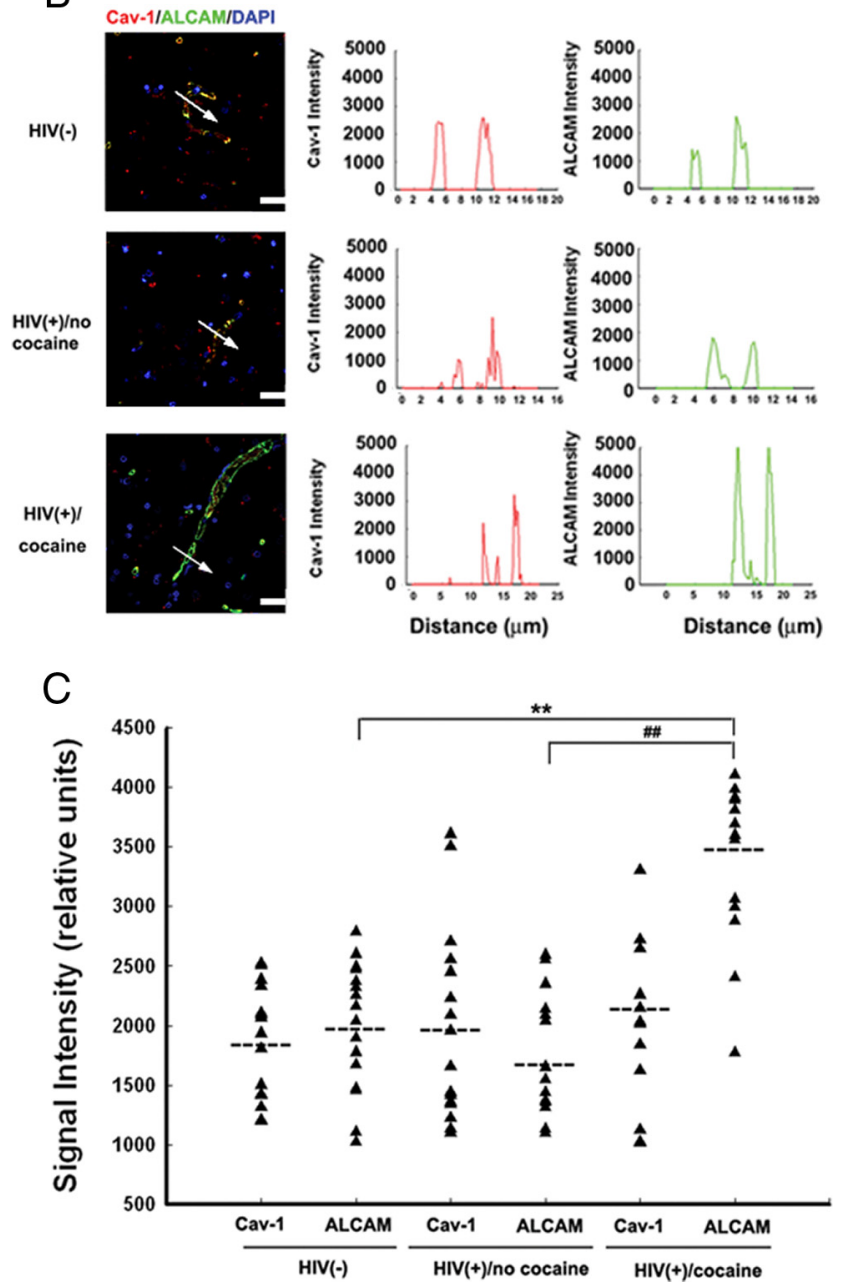

Figure 1. Cocaine-mediated induction of ALCAM expression in human brains. $\boldsymbol{A}$, Increased accumulation of CD68-positive cells around the microvessel that stained positive for ALCAM in drug-abusing $\mathrm{HIV}^{+}$individuals (bottom panel) compared with $\mathrm{HIV}^{-}$or $\mathrm{HIV}^{+}$with no drug abuse history. Confocal microscopy of paraffin-embedded sections of the basal ganglia from $\mathrm{HIV}^{-}$(top panel), $\mathrm{HIV}^{+}$/no drug abuse history (middle panel), or HIV ${ }^{+} /$drug abusers stained with antibodies specific for CD68 (red) and ALCAM (green). Scale bar, $20 \mu \mathrm{m}$. Representative figures were shown from four experiments with four $\mathrm{HIV}^{-}$, three $\mathrm{HIV}^{+}$/no drug abuse, and four $\mathrm{HIV}^{+}$/drug abusers. B, ALCAM expression was upregulated in the CNS vessels of HIV ${ }^{+}$ individuals with drug (cocaine) abuse history (bottom panel). Confocal microscopy of paraffin- man et al., 1988; Chaudhuri et al., 2008b). Freshly elutriated monocytes were cultured in DMEM containing 10\% heat-inactivated human serum, $2 \mathrm{mmol} / \mathrm{L} \mathrm{L}$-glutamine (Invitrogen), $100 \mathrm{mg} / \mathrm{ml}$ gentamicin, and 10 $\mathrm{mg} / \mathrm{ml}$ ciprofloxacin (Sigma-Aldrich), and were exposed to HIV-1ADA at a multiplicity of infection of 0.01 and used for coculture experiments at day 5 after infection.

For monocyte adhesion as previously reported (Ramirez et al., 2008, 2010), HBMECs were seeded on 96-well plates at a density of $2.5 \times 10^{4}$ cells/well and after confluence were treated with different concentrations of cocaine for $24 \mathrm{~h}$. HIV-infected or noninfected monocytes at $5 \times 10^{6}$ cells $/ \mathrm{ml}$ were labeled with $10 \mu \mathrm{M}$ CellTracker Green (Invitrogen) for 10 min. Monocytes and HBMECs were then incubated for $15 \mathrm{~min}$ and rinsed three times with PBS to eliminate the nonadherent monocytes. The fluorescence intensity of adherent monocytes was measured using a Synergy Mx fluorescence plate reader (Bio-Tek Instruments).

For monocyte transmigration, cells were washed with PBS and fluorescently labeled with $10 \mu \mathrm{M}$ CellTracker Green (Invitrogen) for $10 \mathrm{~min}$ at room temperature. Labeled cells $\left(2 \times 10^{5}\right.$ cells $)$ were added to the upper compartments of Transwell inserts and allowed to transmigrate at $37^{\circ} \mathrm{C}$ in a humid atmosphere of $5 \% \mathrm{CO}_{2}$ for $24 \mathrm{~h}$. Transmigrated monocytes were counted by two individuals "blinded" to the identity of the treatment group according to previously published reports (Eugenin et al., 2006; Kanmogne et al., 2007; Cayrol et al., 2008; Chaudhuri et al., 2008a; Ramirez et al., 2010).

Transduction with adenovirus constructs. HBMECs were transduced with adenoviral constructs containing either the WT or DN forms of Akt. In addition, HBMEC cells were also transduced with recombinant adenovirus vectors coexpressing both GFP and full-length RelA (RelAFL), or GFP and a transcriptionally inert RelA mutant (RelA1-300) used at a multiplicity of infection of 50 as previously described (Kaul et al., 2007).

Western blotting. Treated cells were lysed using the Mammalian Cell Lysis kit (Sigma-Aldrich) and the NE-PER Nuclear and Cytoplasmic Extraction kit (Pierce). Equal amounts of the corresponding proteins were electrophoresed in a SDS-polyacrylamide gel (12\%) in reducing conditions followed by transfer to PVDF (polyvinylidene difluoride) membranes. The blots were blocked with 5\% nonfat dry milk in PBS. The Western blots were then probed with antibodies recognizing the phosphorylated forms of PDGF- $\beta$ R, c-Src, extracellular signal-regulated kinase 1/2 (ERK1/2), JNK, p38, Akt, NF- $\kappa$ B p65 (1:200; Cell Signaling), ALCAM (1:1000; sc-25624; Santa Cruz Biotechnology), GM1 (1:1000; gift from A. Prat), and $\beta$-actin (1:4000; Sigma-Aldrich). The secondary antibodies were alkaline phosphatase conjugated to goat anti-mouse/ rabbit IgG (1:5000). Signals were detected by chemiluminescence (Yao et al., 2009a).

Immunoprecipitation. The procedure for immunoprecipitation was performed as described previously (Yao et al., 2009c). HBMECs with different treatments were lysed in RIPA buffer (50 mM Tris, pH 8.0, 150 $\mathrm{mm} \mathrm{NaCl}, 0.1 \%$ SDS, $1.0 \% \mathrm{NP}-40$, and $0.5 \%$ sodium deoxycholate) containing proteinase and phosphatase inhibitors. For each sample, $200 \mu \mathrm{g}$ of protein was used for coimmunoprecipitation. Sample protein was incubated with $2 \mu \mathrm{g}$ of diluted anti-4G10 (Millipore) overnight at $4^{\circ} \mathrm{C}$ followed by incubation with $20 \mu \mathrm{l}$ of protein A-Sepharose for $3 \mathrm{~h}$ at $4^{\circ} \mathrm{C}$. The mixture was then centrifuged (at $6000 \times g$ for $30 \mathrm{~s}$ ) and the cell pellets were rinsed twice with RIPA, followed by boiling in $2 \times$ Western blot loading buffer for $4 \mathrm{~min}$. After spinning (at $6000 \times \mathrm{g}$ for $30 \mathrm{~s}$ ), the supernatants were subjected to Western blot analysis as described above.

Bone marrow-derived monocyte isolation and cultivation. Male C57BL/ 6 mice (Charles River Laboratories), $4-5$ weeks of age, were used

embedded sections of the basal ganglia from $\mathrm{HIV}^{-}$(top panel), $\mathrm{HIV}^{+}$/no drug abuse (middle panel), or $\mathrm{HIV}^{+} / \mathrm{drug}$ abusers stained with antibodies specific for Cav-1 (red), ALCAM (green), nuclei are stained with DAPI (4', 6' -diamidino-2-phenylindole) (blue). Scale bar, $20 \mu \mathrm{m}$. Semiquantitative analysis of the signal intensity from $3 \mu \mathrm{m} z$-stack reconstructions along the line markers in the images in left panels. C, Peak fluorescence intensity averaged from two distinct measurements on each vessel. Each symbol represents one vessel image; small horizontal lines indicate the mean. ${ }^{* *} p<0.01$ versus $\mathrm{HIV}^{-}$group; ${ }^{\# \#} p<0.01$ versus $\mathrm{HIV}^{+} /$no drug abuse group counted from 12 vessels per group. 

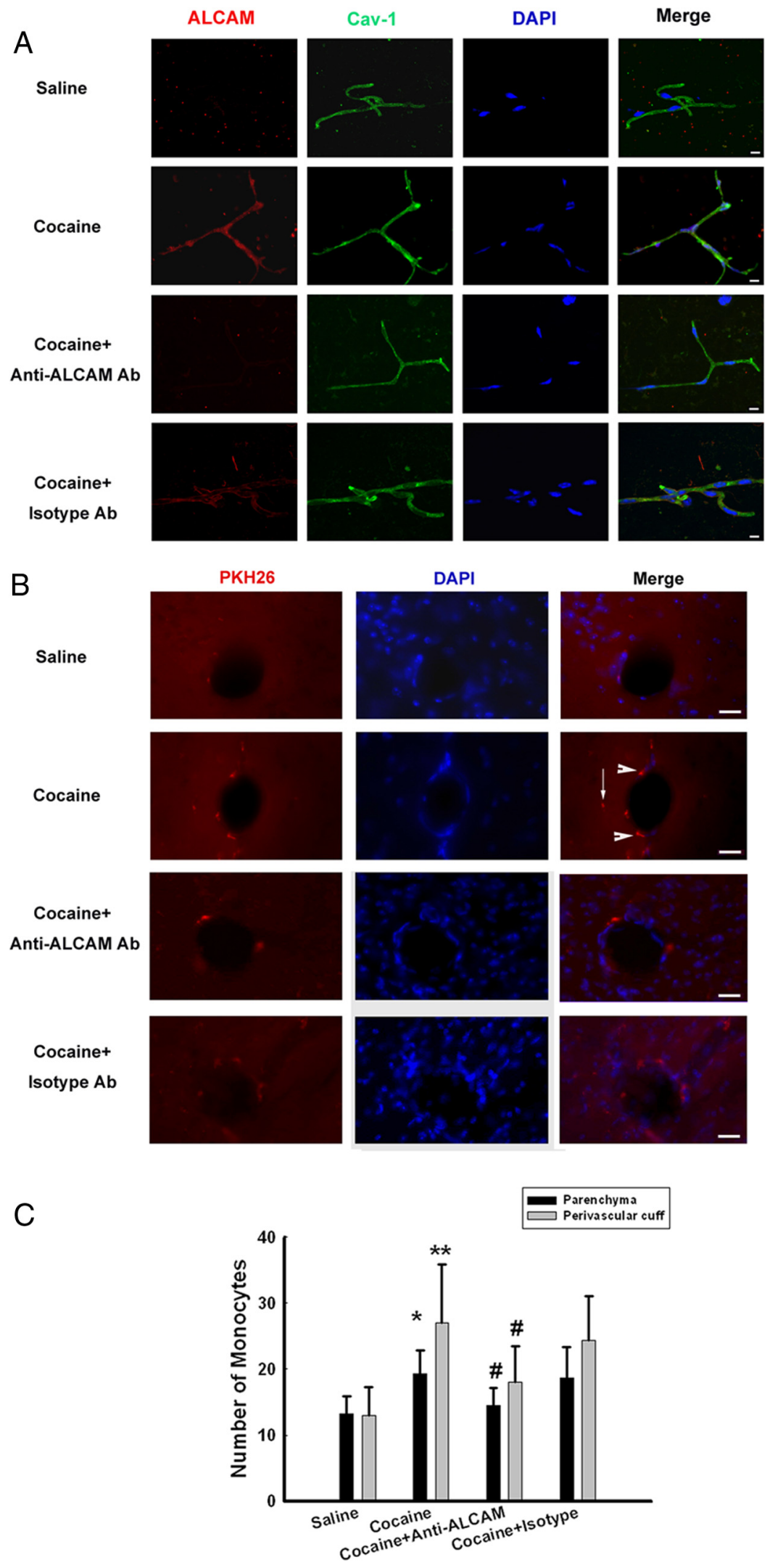

Figure 2. Cocaine-mediated induction of ACLAM enhances monocyte adhesion and transmigration in vivo. A, Cocaine induced increased expression of ALCAM in isolated microvessels compared with those from saline-injected animals (top panels). ALCAM, red; Cav-1, green; nuclei, blue. $n=6$ per group. $\boldsymbol{B}$, Representative fluorescence micrographs demonstrating cocaine-mediated adhesion of PKH26labeled monocytes in the perivascular cuff(see arrowheads) and the parenchymal (seearrows) areas of the mice brain. C, Cocaine-mediated increased monocyte transmigration was ameliorated in mice pretreated with ALCAM neutralizing antibody. ${ }^{*} p<0.05,{ }^{* *} p<0.01$ versus saline group; $" p<0.05$ versus cocaine group counted from the perivascular cuff and parenchyma. Error bars indicate SEM. as bone marrow-derived monocyte (BMM) donors. Briefly, the femur was removed, bone marrow cells were dissociated into single-cell suspensions and were cultured for $10 \mathrm{~d}$ supplemented with $1000 \mathrm{U} / \mathrm{ml}$ M-CSF (Wyeth). Cultured BMMs proved to be $98 \% \mathrm{CD} 1 \mathrm{~b}^{+}$by flow-cytometric analysis using a FACSC flow cytometer (BD Biosciences). For tracking experiments, cells were labeled with the membrane dye $\mathrm{PKH} 26$ according to the manufacturer's instructions (Sigma-Aldrich).

In vivo monocyte transmigration assay. Assay of monocyte transmigration into the brain was performed in C57BL/6 mice. Animals were divided into four groups $(n=6)$ : (1) saline, (2) cocaine, (3) cocaine plus anti-ALCAM, and (4) cocaine plus isotope control antibody. Cocaine was injected at a dose of $20 \mathrm{mg} / \mathrm{kg}$ intraperitoneally for $7 \mathrm{~d}$. For the ALCAM neutralizing antibody study, mice were injected with cocaine for $7 \mathrm{~d}$ as described above; additionally, on days 3,5 , and 7 of cocaine injection, coadministration of either anti-ALCAM or isotope control antibody $(250 \mu \mathrm{g}$ each, i.p; monoclonal MAB 656 or mouse IgG1, MAB 002; R\&D Systems) was also performed. Antibody concentrations and treatment regimens were based on a previously published report (Cayrol et al., 2008). On the eighth day after cocaine injection, animals were injected with PKH 26-labeled BMMs at a concentration of $10^{7}$ cells $/ 100 \mu$ l through tail vein. Twenty-four hours after cell infusion, the animals were killed and subjected to transcardial perfusion with saline to remove labeled monocytes from tissue blood vessels. Brain tissues were then removed and frozen at $-80^{\circ} \mathrm{C}$ until cryosection. In all the six animals per group, perivascular and parenchyma were counted in the entire area of the three coronal brain sections: 1.94, 1.34, and $0.14 \mathrm{~mm}$ to bregma according to the previously described report (Schilling et al., 2009).

Microvessel isolation and immunofluorescence staining. Brain microvessels were isolated as described previously (Huang et al., 2010). Under anesthesia, animals were perfused with saline; the brains were removed and immediately immersed in ice-cold isolation buffer $\mathrm{A}$ [103 mm NaCl, $4.7 \mathrm{~mm} \mathrm{KCl}, 2.5 \mathrm{~mm} \mathrm{CaCl}_{2}, 1.2$ $\mathrm{mM} \mathrm{KH} \mathrm{PO}_{4}, 1.2 \mathrm{~mm} \mathrm{MgSO}_{4}$, and $15 \mathrm{~mm}$ HEPES, pH 7.4, with Complete Protease Inhibitor (Roche)]. The choroid plexus, meninges, cerebellum, and brainstem were removed, followed by homogenization of the brains in $5 \mathrm{ml}$ of isolation buffer B [buffer A with $25 \mathrm{~mm}$ $\mathrm{NaHCO}_{3}, 10 \mathrm{~mm}$ glucose, $1 \mathrm{~mm}$ Na-pyruvate, and dextran (molecular weight, $64 \mathrm{kDa} ; 10$ g/L); pH 7.4] with Complete Protease Inhibitor. Twenty-six percent dextran was then added to the homogenates, followed by centrifugation at $5800 \times g$ for $20 \mathrm{~min}$. Cell pellets were resuspended in isolation buffer $B$ and filtered through a $70 \mu \mathrm{m}$ mesh filter (BD Biosciences). Filtered homogenates were repelleted by centrifugation and smeared on slides.

For immunofluorescence staining, brain microvessels smeared on slides were fixed for $10 \mathrm{~min}$ at $95^{\circ} \mathrm{C}$, followed by incubation with 

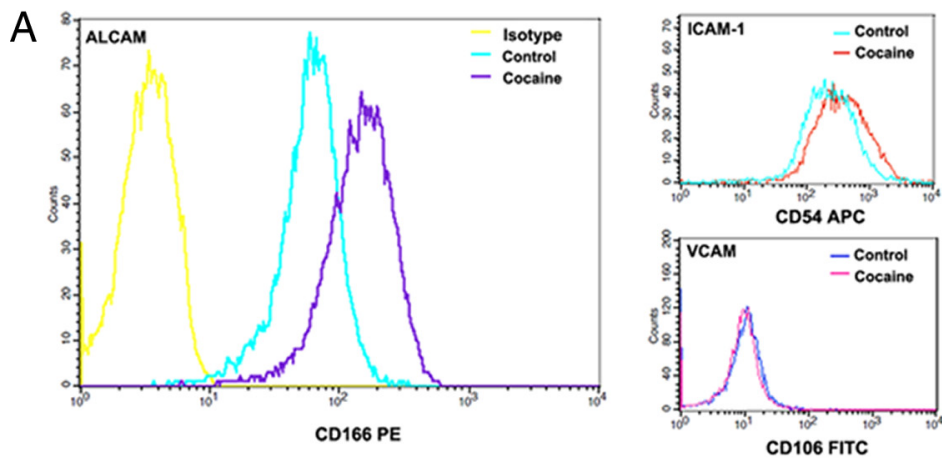

B

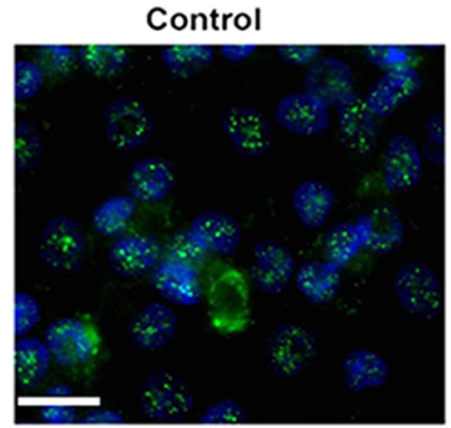

Cocaine

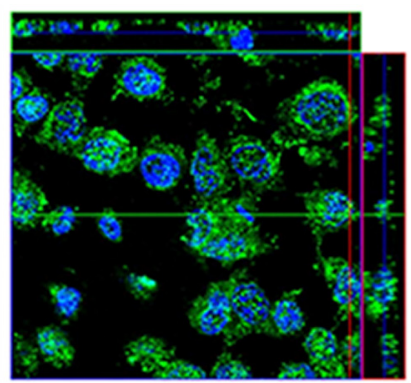

C

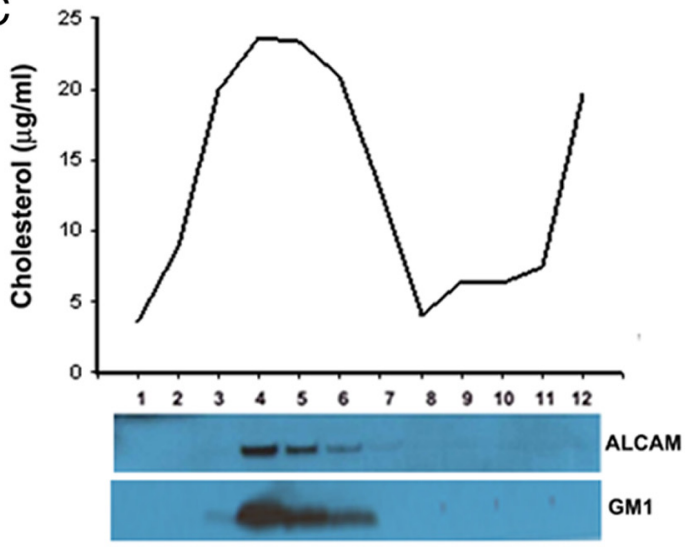

D

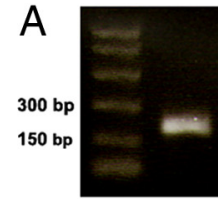

B

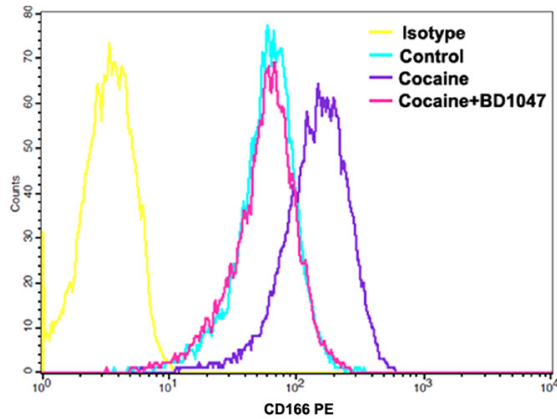

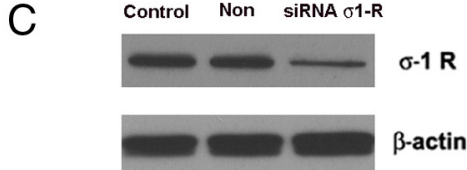

D

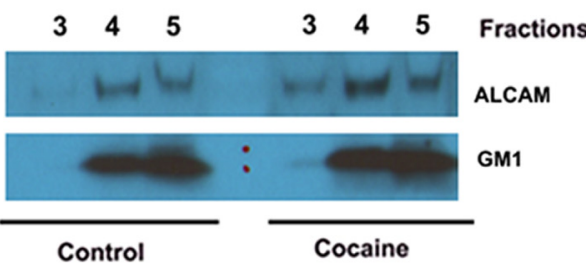

Figure 3. Cocaine-mediated induction of ALCAM expression and its translocation to lipid rafts. $A$, Flow-cytometric analysis indicating cocaine-mediated changes in ALCAM, ICAM, and VCAM in HBMECs. B, ALCAM expression (green) in cocaine-treated HBMECs. Nuclei were stained with DAPI (blue). Scale bar, $20 \mu \mathrm{m}$. C, ALCAM localization in cholesterol-rich lipid raft fractions (4-5) of HBMECs. Presence of cholesterol confirms the lipid raft nature of fractions $4-5$. D, Cocaine promoted increased translocation of ACLAM into lipid raft fractions. All of the experiments were repeated at least four separate times.

$3 \%$ formaldehyde in PBS for $10 \mathrm{~min}$ at $25^{\circ} \mathrm{C}$. The slides were washed five times with PBS, permeabilized with $0.1 \%$ Triton X-100 for 30 min, rewashed five times in PBS, and blocked BSA in PBS for $30 \mathrm{~min}$ at $25^{\circ} \mathrm{C}$. SamCAM (polyclonal rabbit; 1:100 dilution; sc25624; Santa Cruz Biotechnology) and caveolin-1 (Cav-1) (monoclonal mouse; 1:100 dilution; sc-70516; Santa Cruz Biotechnology) antibodies (1:100) overnight at $4^{\circ} \mathrm{C}$. The slides were washed with PBS and incubated with Alexa Fluor 594-conjugated anti-rabbit or Alexa Fluor 488-conjugated anti-mouse IgG for $1 \mathrm{~h}$ at room temperature. After a final washing with PBS, the slides were mounted with ProLong Gold Antifade reagent to visualize the nuclei as previously reported (Huang et al., 2010). The immunofluorescent images were captured using confocal microscopy.

Tissue and immunostaining. Formalin-fixed, paraffin-embedded sections $(5 \mu \mathrm{m})$ of basal ganglia from $\mathrm{HIV}^{-}, \mathrm{HIV}^{+}$, and $\mathrm{HIV}^{+} /$drug abusers (cocaine included) were obtained from the National NeuroAIDS Tissue Consortium and stained with antibodies specific for ALCAM (polyclonal goat; 1:40 dilutions; AF1172; R\&D Systems), Cav-1 (monoclonal mouse; 1:100 dilution; sc-70516; Santa Cruz Biotechnology), or CD-68 (1:100; Dako). Sections were washed thrice in PBS followed by incubation in secondary Alexa Fluor 488 donkey anti-goat antibody (1:200) and Alexa Fluor 594 goat anti-mouse antibody (1:200) or Alexa Fluor 594 goat anti-rabbit antibody (1:200). For quantification of ALCAM and Cav-1 signal, $Z$-stack images were acquired on a Carl Zeiss confocal
Figure 4. Engagement of $\sigma 1 \mathrm{R}$ is critical for cocaine-mediated induction of ALCAM expression. $\boldsymbol{A}$, Detection of $\sigma 1 \mathrm{R}$ RNA by RT-PCR analysis in HBMECS. $\boldsymbol{B}$, Flow analysis of ALCAM expression in cocaine-exposed HBMECS pretreated with/without $\sigma 1 \mathrm{R}$ antagonist BD1047 $(20 \mu \mathrm{M})$. C, Whole-cell lysates from HBMECs transfected with either $\sigma 1$ R or nonsense (Non) siRNAs subject to Western blot analysis. $D, \sigma 1 R$ siRNA, but not non-siRNA, inhibited cocaine-mediated induction of ALCAM expression. All of the data are presented as mean \pm SD of four independent experiments. ${ }^{*} p<0.05$ versus control group; ${ }^{\# \#} p<0.01$ versus cocainetreated HBMECs in nonspecific siRNA group. Error bars indicate SEM.

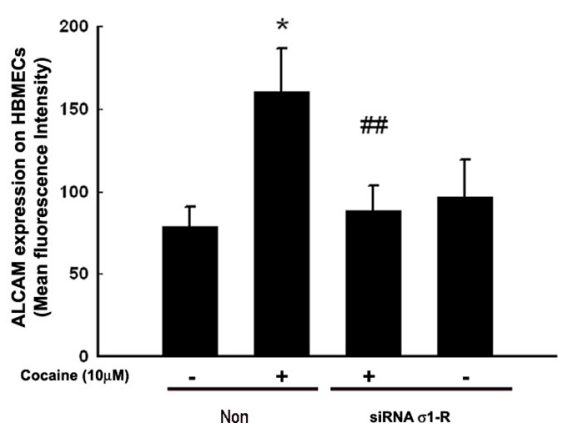

laser-scanning microscope and were analyzed with LSM 510 software (release version $4.0 \mathrm{SP} 1$ ). Signal intensities were collected in duplicate, and microscopy data were acquired by two investigators "blinded" to the intensity of the disease group.

Statistical analysis. Statistical analysis was performed using one-way ANOVA with a post hoc Student $t$ test. Results were judged statistically significant if $p<0.05$ by ANOVA. 
A

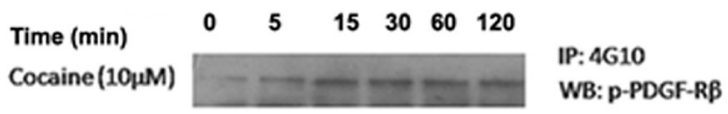

B

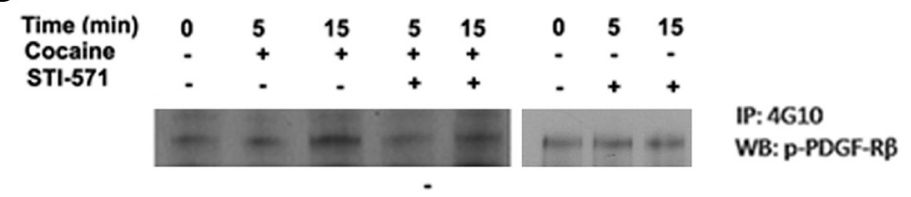

C

Cocaine BD1047

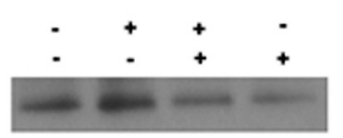

IP: 4 G10

WB: $\mathrm{p} \cdot \mathrm{PDGF}-\mathrm{RB}$

$\mathrm{E}$

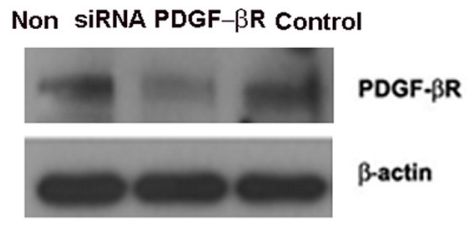

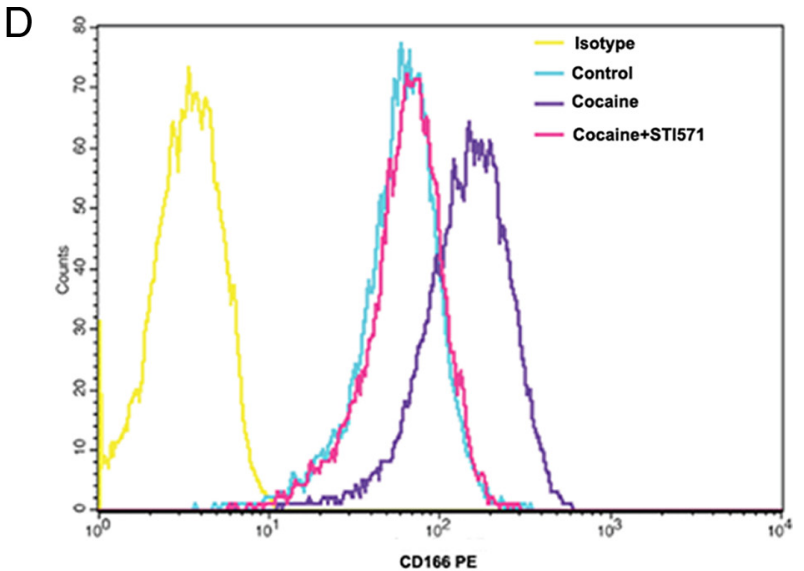

$\mathrm{F}$

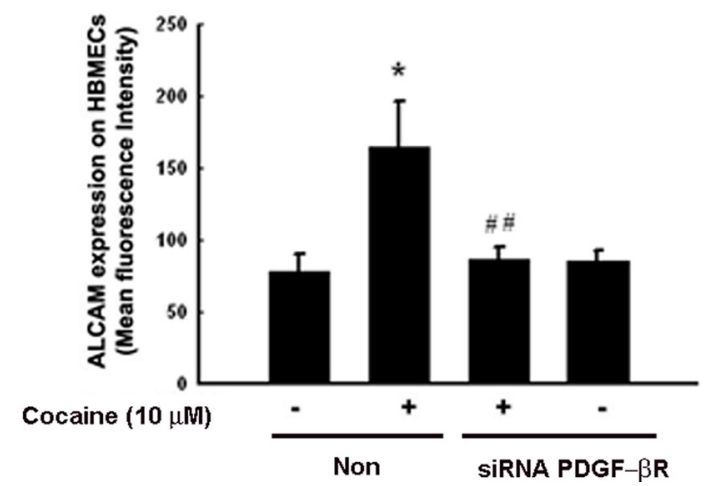

Figure 5. Cocaine-mediated induction of ALCAM involves PDGF- $\beta$ R activation. $A$, Cocaine mediated time-dependent phosphorylation of PDGF- $\beta R$. $B$, Inhibition of cocaine-mediated phosphorylation of PDGF- $\beta$ R by the tyrosine kinase inhibitor STI-571 $(1 \mu \mathrm{M})$. C, Inhibition of cocaine-mediated phosphorylation of PDGF- $\beta$ R by BD1047 (20 $\mu \mathrm{m})$ in HBMECs. D, Flow analysis demonstrating abrogation of cocaine-mediated induction of ALCAM in HBMECs pretreated with STI-571. E, Knockdown of PDGF- $\beta$ R expression in HBMECs transfected with PDGF- $\beta$ R siRNA but not Non siRNA. $F$, PDGF- $\beta$ R siRNA, but not non-siRNA, inhibited cocaine-mediated induction of ALCAM expression. All the data are presented as mean $\pm S D$ of four independent experiments. ${ }^{*} p<0.05$ versus control group; $\#$ $p<0.01$ versus cocaine-treated HBMECs in nonspecific siRNA group. Error bars indicate SEM.

\section{Results}

Upregulation of ALCAM expression in caveolin-rich microvessels from HIV-infected drug (cocaine) abusers Since the degree of neurological deficit in HIV-infected individuals is strongly correlated with the number of activated macrophages and microglia within the basal ganglia, we verified the CD68-positive staining in postmortem brain tissues from $\mathrm{HIV}^{-}$, $\mathrm{HIV}^{+}$/no cocaine, and $\mathrm{HIV}^{+}$/cocaine drug abusers. Because of the inherent difficulty of finding tissues from unidrug abusers, we resorted to samples from polydrug abusers that included a history of cocaine abuse. To establish clinical relevance of ALCAM expression in the context of HIV-1 infection with drug (cocaine) abusers, we examined ALCAM expression and double labeling with CD68. As shown in Figure 1A, the increased CD68 immunostaining seen in $\mathrm{HIV}^{+} /$cocaine drug abusers paralleled with upregulation of ALCAM in the brain endothelium compared with $\mathrm{HIV}^{+}$/no cocaine or uninfected controls. This new finding suggested that ALCAM plays a role in promoting leukocyte infiltration across the BBB.

For additional validation of upregulated expression of ALCAM, sections from basal ganglia region of the brain were stained for both ALCAM and Cav-1 (endothelial cell membrane marker). ALCAM expression, although weak in microvessels from both $\mathrm{HIV}^{-}$and $\mathrm{HIV}^{+} /$no cocaine individuals, was significantly enhanced in vessels from $\mathrm{HIV}^{+} /$cocaine drug abusers. Merged images of ALCAM and Cav-1 staining confirmed colocalization of ALCAM on the surface of endothelial cells (sup- plemental Fig. 1, available at www.jneurosci.org as supplemental material).

Cav-1 and ALCAM signal intensities in CNS blood vessels from $\mathrm{HIV}^{-}$(Fig. $1 B$, top panel), $\mathrm{HIV}^{+} /$no cocaine (Fig. $1 B$, middle panel), and $\mathrm{HIV}^{+} /$cocaine drug abusers (Fig. $1 B$, bottom panel) were quantified by recording $x-y$ planar images $(0.1 \mu \mathrm{m}$ in thickness) on two distinct channels, followed by reconstruction of $3 \mu \mathrm{m} z$-stack images. ALCAM staining was significantly stronger in $\mathrm{HIV}^{+} /$cocaine drug abusers compared with the $\mathrm{HIV}^{-}$or the $\mathrm{HIV}^{+} /$no cocaine group (Fig. 1C). Intriguingly, there was no significant change in the expression of other adhesion molecules such as ICAM-1 or VCAM-1 in the brains tissues in response to cocaine as shown in supplemental Figures 2 and 3 (available at www.jneurosci.org as supplemental material), thus underscoring the specificity of ALCAM induction by cocaine.

\section{ALCAM promotes monocyte adhesion and transmigration in} mice treated with cocaine

To further validate cocaine-mediated induction of ALCAM in vivo, we examined the expression level of ALCAM in brain capillaries isolated from cocaine- versus saline-treated mice. After administration of cocaine, there was an increase in the expression level of ALCAM in isolated microvessels from cocaine-exposed mice compared with controls (Fig. 2A).

Since ALCAM expression was increased in cocaine-treated mice, to validate the role of ALCAM in monocyte transmigration in vivo, mice were treated with cocaine, followed by tail vein 
A
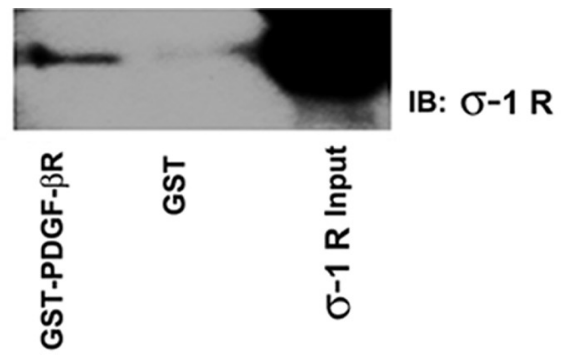

B
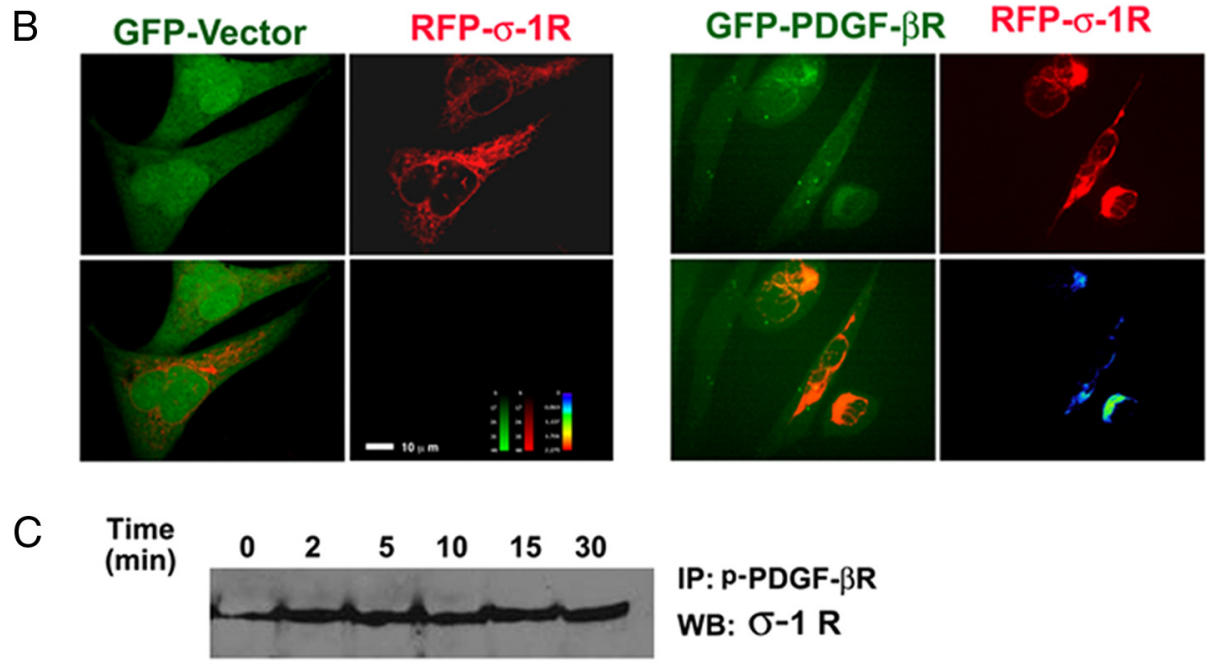

\section{IP: P-PDGF- $\beta$ R \\ WB: $\sigma-1 \mathbf{R}$}

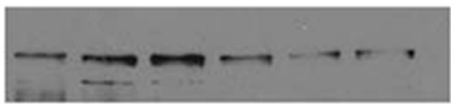

IP: $\sigma-1 \mathbf{R}$

WB:p-PDGF- $\beta R$
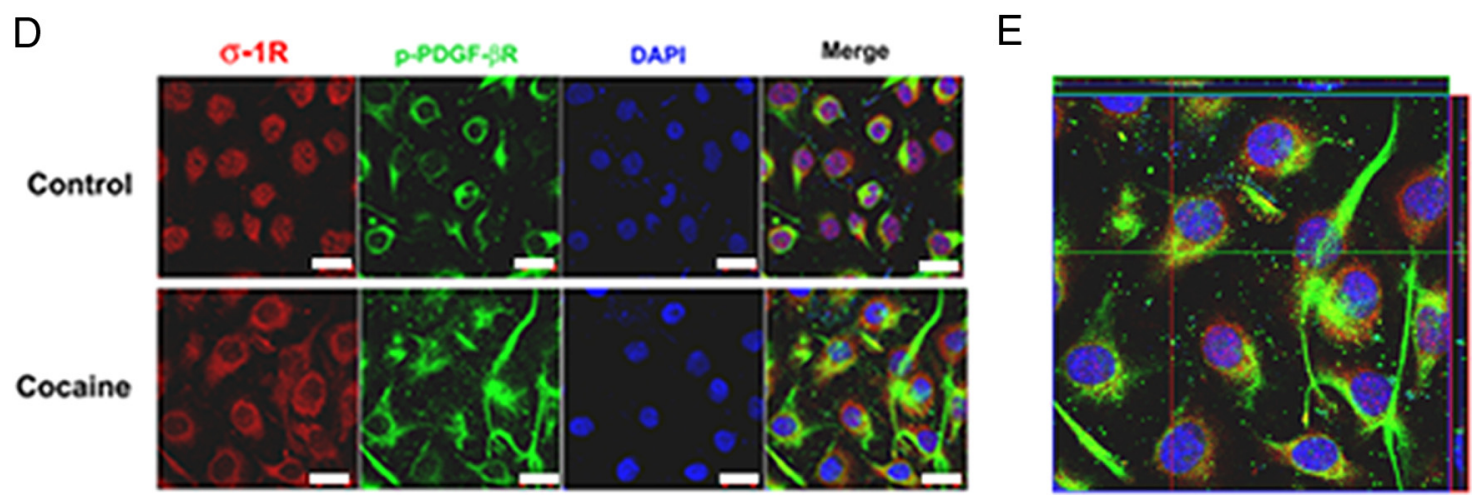

Figure 6. Interaction of $\sigma 1$ R and PDGF- $\beta$ R. $A$, Pulldown assay with GST fusion protein to identify the binding of $\sigma 1$ R and PDGF- $\beta$ R. $B$, FRET analysis of the interaction between PDGF- $\beta$ R and $\sigma 1$ R. Negative control of CHO cells expressing GFP and $\sigma 1 \mathrm{R}$-RFP. Top left, GFP; top right, $\sigma 1 \mathrm{R}$-RFP; bottom left, merged image; bottom right, normalized FRET with a scale and references of fluorescent intensities (left panel). FRET in CHO cells expressing PDGF- $\beta$ R-GFP and $\sigma$-1 R-RFP. Top left, PDGF- $\beta$ R-GFP; top right, $\sigma 1$ R-RFP; bottom left, merged image; bottom right, normalized FRET. The scale (scale bar, $10 \mu \mathrm{m}$ ) and references are the same to $\boldsymbol{A}$ (right panel). $C$, Cocaine affects the interaction between $\sigma 1$ R and PDGF- $\beta$ R using coimmunoprecipitation assay. $\boldsymbol{D}$, HBMECs were treated with cocaine and double stained using antibodies specific for $\sigma 1 \mathrm{R}$ (red) or PDGF- $\beta R$ (green). Nuclei were stained with DAPI (blue). Representative pictures from three typical experiments. Scale bars, $20 \mu \mathrm{m}$. E, Z-stack reconstruction was used for analysis of $\sigma 1 \mathrm{R}$ and PDGF- $\beta$ R colocalization (yellow) in HBMECs.

injection of labeled mouse BMM and their detection in the brain. Of particular note, the distribution of labeled monocytes was primarily within the perivascular cuffs (Fig. $2 B$, arrowheads), with some localization in the parenchyma (Fig. $2 B$, arrows). Quantification of the brain sections revealed increased transmigration in the CNS of cocaine-treated mice compared with controls. Specificity of ALCAM action was further demonstrated in mice pretreated with the neutralizing antibody to ALCAM. Monocyte transmigration in these mice was ameliorated lending additional support to the role of ALCAM (Fig. 2C).

\section{Cocaine-mediated upregulation of ALCAM protein} in HBMECs

To better understand how cocaine regulates ALCAM expression, we examined the effects of cocaine on ALCAM induction in HBMECs. As an initial screening study to identify the effective concentration of cocaine on ALCAM expression, HBMECs were treated with varying concentrations of cocaine $(1,10$, and 100 $\mu \mathrm{M}$ ) with a maximal response at $10 \mu \mathrm{M}$ (supplemental Fig. $4 \mathrm{~A}$, available at www.jneurosci.org as supplemental material). This concentration of cocaine was therefore chosen for all of our 


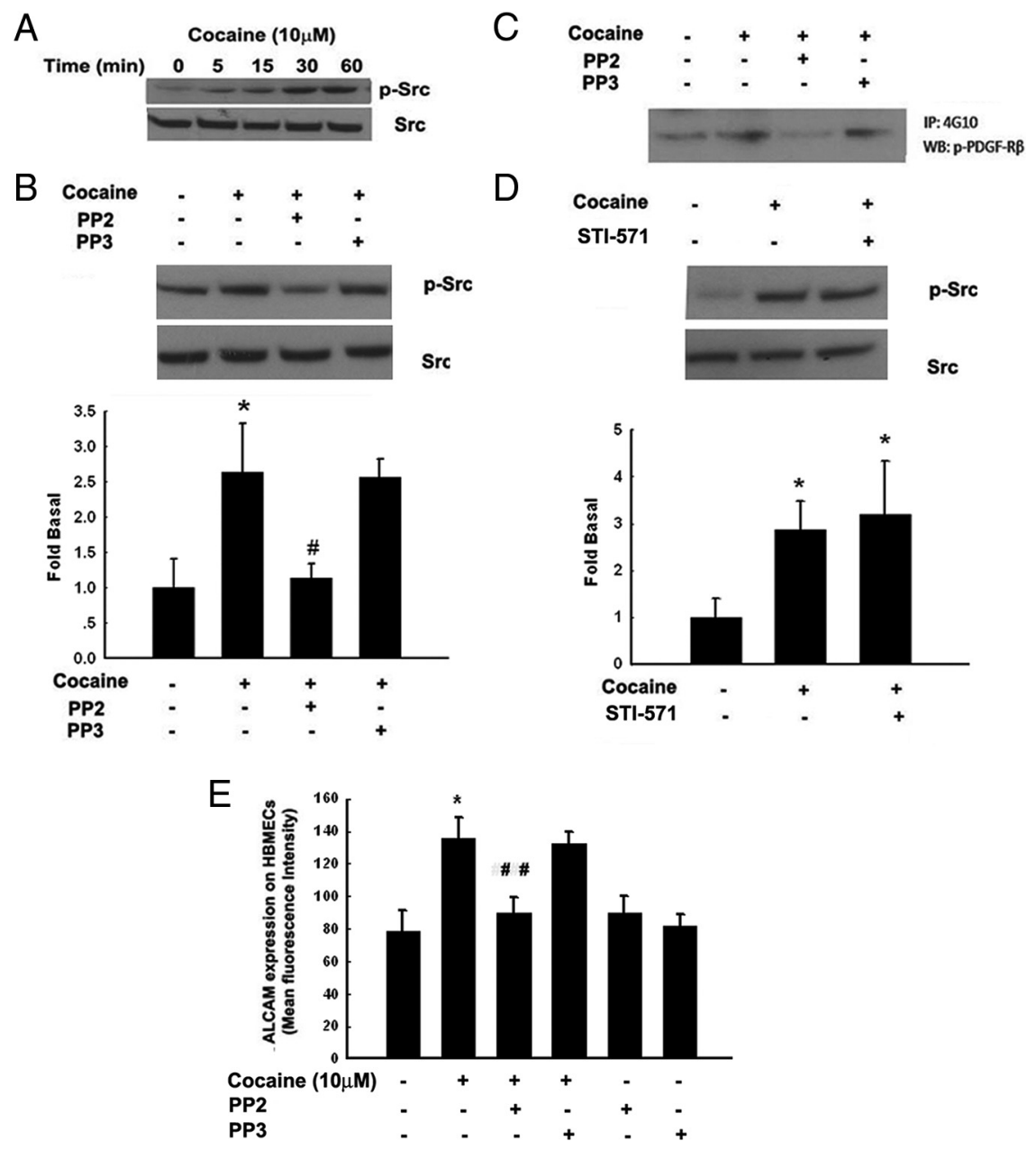

Figure 7. Cocaine-mediated induction of ALCAM involves activation of c-Src tyrosine kinase. $\boldsymbol{A}$, Cocaine-mediated timedependent phosphorylation of c-Src in HBMECS. $\boldsymbol{B}$, Pretreatment of HBMECs with Src kinase inhibitor PP2 (10 $\mu$ M), but not PP3 (1 $\mu \mathrm{M})$, abrogated cocaine-induced phosphorylation of c-Src. C, Western blot analysis demonstrating inhibition of cocaine-mediated phosphorylation of PDGF- $\beta$ R in HBMECs pretreated with the Src inhibitor PP2, but not PP3. D, Western blot analysis demonstrating inability of the STI-571 (1 $\mu \mathrm{m})$ to inhibit cocaine-mediated phosphorylation of c-Src in HBMECs. $\boldsymbol{E}$, Quantification of flowcytometric analysis demonstrating abrogation of cocaine-mediated induction of ALCAM in HBMECs pretreated with the Src kinase inhibitor PP2 (10 $\mu \mathrm{m})$, but not with the Src kinase ortholog PP3 (1 $\mu \mathrm{m})$. All the data are presented as mean \pm SD of four independent experiments. ${ }^{*} p<0.05$ versus control group; ${ }^{\#} p<0.05,{ }^{\# \#} p<0.01$ versus cocaine-treated group. Error bars indicate SEM.

additional studies. The next step was to examine the time course of ALCAM induction. Cocaine-mediated induction of ALCAM was observed as early as $6 \mathrm{~h}$ after treatment and was significantly upregulated even at $24 \mathrm{~h}$ after treatment in HBMECs (shown in supplemental Fig. $4 B, C$, available at www. jneurosci.org as supplemental material). Furthermore, using flow cytometry, it was demonstrated that under normal conditions HBMECs expressed almost equal levels of ALCAM and ICAM-1, and lower levels of VCAM-1 (Fig. 3A). Intriguingly, activation of cells with cocaine elicited robust upregulation of ALCAM, but a weaker induction of ICAM-1 (Fig. 3A).

The next step was to examine the distribution of ALCAM on these cells. As evidenced by confocal microscopy (Fig. 3B), after cocaine exposure, ALCAM immunoreactivity concentrated around the plasma membrane. Since ALCAM is present in cholesterol-enriched membrane microdomains (Cayrol et al., 2008), as expected, ALCAM was primarily recruited to cholesterol-enriched membrane microdomains (fractions 4-5), positive for ganglioside marker of lipid raft, GM1 (Fig. 3C). After cocaine treatment, ALCAM expression in lipid raft fractions of HBMECs was increased significantly compared with controls (Fig. 3D).

\section{Engagement of $\sigma 1$ receptor is critical for cocaine-induced ALCAM expression} $\sigma 1$ receptor $(\sigma 1 \mathrm{R})$ belonging to the nonopioid receptor family binds to diverse classes of psychotropic drugs including cocaine (Hayashi and Su, 2003). As shown by reverse transcription (RT)-PCR (Fig. $4 A$ ) and Western blotting (Fig. 4C), HBMECs expressed $\sigma 1 \mathrm{R}$ mRNA and protein. Cocaine-mediated induction of ALCAM was significantly attenuated by pretreatment of cells with the $\sigma 1 \mathrm{R}$ antagonist BD1047 (Fig. 4B). Transfection of cells with $\sigma 1 \mathrm{R}$ siRNA also resulted in significant knockdown of expression of $\sigma 1 \mathrm{R}$ (Fig. 4C) with significant abrogation of cocaine-mediated induction of ALCAM expression (Fig. 4D).

\section{Exposure of HBMECs to cocaine activates PDGF- $\boldsymbol{\beta}$ R}

Engagement of $\sigma 1 \mathrm{R}$ can regulate both the activation and signaling of tyrosine kinase receptors, including $\mathrm{PDGF}-\beta \mathrm{R}$, which in turn, regulate the expression of cell adhesion molecules (C. C. Lin et al., 2007). We thus rationalized that the cocaine $/ \sigma 1 \mathrm{R}$ dyad could result in activation of PDGF- $\beta$ R and, subsequently, induction of ALCAM. Lysates from HBMECs treated with cocaine induced timedependent phosphorylation of PDGF- $\beta \mathrm{R}$ at Tyr 751 (Fig. 5A), which was abrogated by both STI-571 (Fig. 5B) and BD1047 (Fig. 5C). Pretreatment with STI-571 (Fig. 5D) and transfection with PDGF- $\beta \mathrm{R}$ siRNA (Fig. 5E,F) attenuated ALCAM expression.

These findings were further validated using human phosphoreceptor tyrosine kinase (RTK) antibody arrays specific for PDGF- $\beta$ R (supplemental Table 1, available at www.jneurosci.org as supplemental material). Cocaine specifically induced a greater than twofold increase in phosphorylation of PDGF- $\beta \mathrm{R}$ at Tyr 751. However, phosphorylation of PDGF- $\beta$ R (Tyr 1021 and 741) and PDGF- $\alpha$ R (Tyr 849) were not affected by cocaine. Phosphorylation at Tyr 771 but not Tyr 1009 was also observed with cocaine treatment (supplemental Fig. 5, available at www.jneurosci. org as supplemental material).

\section{Interaction between $\sigma 1 \mathrm{R}$ and PDGF- $\beta \mathrm{R}$}

To explore protein-protein interaction of the two receptors, GST-fusion protein containing PDGF- $\beta$ R was synthesized and used as GST immobilized baits in the pulldown assay. $\sigma 1 \mathrm{R}$ was readily precipitated by GST-PDGF- $\beta$ R (Fig. $6 A$ ).

Protein-protein interaction of $\sigma 1 \mathrm{R}$ and PDGF- $\beta \mathrm{R}$ was further confirmed by FRET analysis. As shown in Figure $6 B$, left panels, $\mathrm{CHO}$ cells transfected with GFP and the $\sigma 1 \mathrm{R}$-RFP failed 
to demonstrate any FRET signal. In contrast, cells cotransfected with both PDGF- $\beta$ R-GFP and $\sigma 1 \mathrm{R}-\mathrm{RFP}$ demonstrated enhanced protein-protein interaction as shown in Figure $6 B$, right panels.

To further assess this interaction, series of coimmunoprecipitations using lysates from cocaine-treated HBMECs were performed. $\sigma 1 \mathrm{R}$-immunoreactive band was consistently seen in the protein precipitated by anti-PDGF- $\beta$ R antibody (Fig. $6 C$, top panel), and reciprocally, PDGF- $\beta \mathrm{R}$ band was displayed in the $\sigma 1 \mathrm{R}$ precipitates (Fig. 6C, bottom panel). These data demonstrate an evident interaction between $\sigma 1 \mathrm{R}$ and PDGF- $\beta \mathrm{R}$ in response to cocaine. Additional validation of this interaction was performed using confocal microscopy. As shown in Figure $6 D$, there was a diffuse pattern of $\sigma 1 \mathrm{R}$ expression in the cytoplasm of untreated HBMECs. Treatment with cocaine resulted in clustering and polarization of $\sigma 1 \mathrm{R}$ with the cell membrane. A $1 \mu \mathrm{m}$ $z$-stack reconstruction demonstrated colocalization of both $\sigma 1 \mathrm{R}$ and PDGF- $\beta \mathrm{R}$ in the presence of cocaine (see merged image and Fig. 6E).

\section{Cocaine-induced expression of ALCAM} involves c-Src activation

Activation of c-Src has been documented as an upstream event of PDGF- $\beta$ R activation (C. C. Lin et al., 2007). We thus examined its involvement in cocaine-mediated activation of PDGF- $\beta$ R and ALCAM induction. Treatment with cocaine resulted in increased c-Src phosphorylation, which was inhibited by Src tyrosine kinase inhibitor PP2, but not by its inactive ortholog PP3 (Fig. 7 $A, B$ ). Intriguingly, cocainestimulated PDGF- $\beta$ R phosphorylation was also blocked by PP2, but not by PP3 (Fig.

7C). In contrast, cocaine-induced activation of Src was not blocked by STI-571 (Fig. 7D), thereby suggesting the role of c-Src activation in transactivation of PDGF- $\beta$ R. Pretreatment with PP2 significantly blocked cocaine-induced expression of ALCAM, thus confirming the role of c-Src in this process (Fig. 7E).

\section{Cocaine-induced expression of ALCAM involves MAPK (ERK1/2, JNK, p38) and PI3K-Akt pathways}

MAPK kinase and PI3K-Akt pathways play critical roles in both cocaine (Yao et al., 2009b) and PDGF- $\beta$ R signaling (F. S. Lin et al., 2005; Yao et al., 2009b). We next examined the involvement of these pathways in cocaine-mediated induction of ALCAM. Treatment with cocaine resulted in time-dependent increase in phosphorylation of MAPK (Fig. 8A) and Akt pathways (Fig. $8 C$ ). Pretreatment of cells with either MEK1/2 (U0126), JNK (SP600125), p38 (SB203580), or PI3K (LY294002) inhibitor resulted in amelioration of cocaine-mediated induction of ALCAM, thus underpinning their roles in the process (Fig. $8 B, D$ ). Additional validation of the Akt pathway in this process was con-

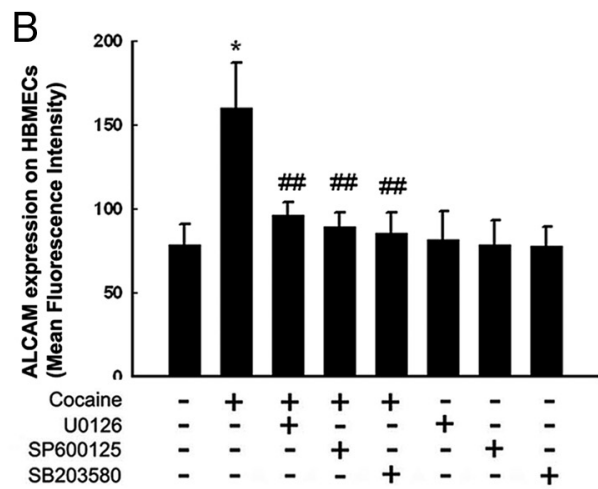

D
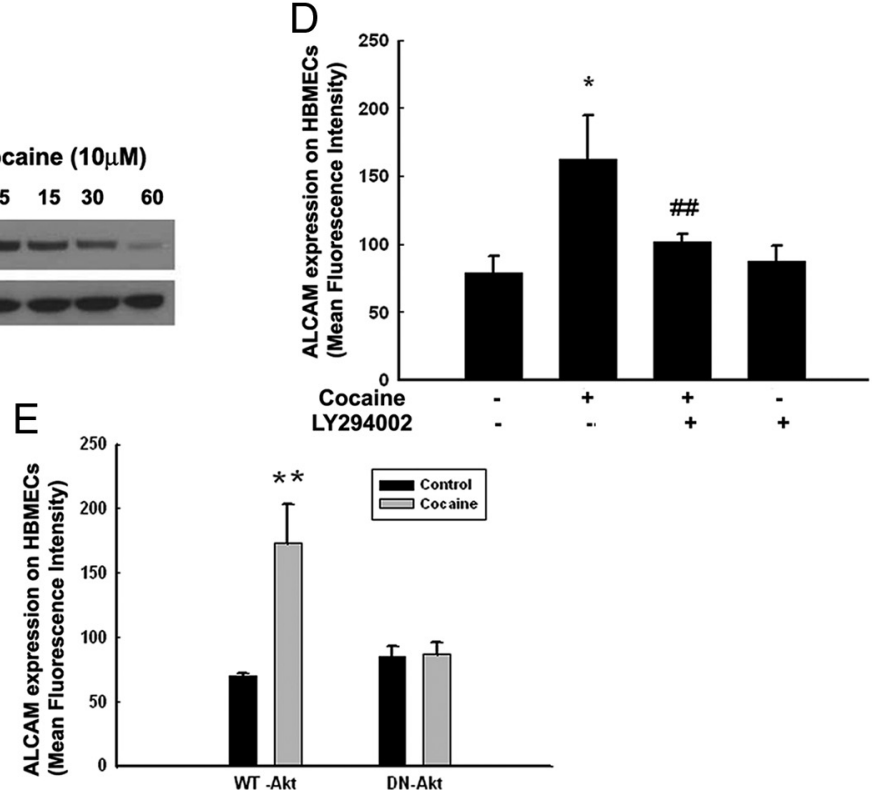

Figure 8. Cocaine-mediated induction of ALCAM expression involves MAPKs and PI3K/Akt cell signaling pathways. $\boldsymbol{A}$, Western blot analysis demonstrating time-dependent activation of ERK, JNK, and $\mathrm{p} 38$ by cocaine. $\boldsymbol{B}$, Inhibition of the ERK and JNK pathway MEK1/2 (U0126, $20 \mu \mathrm{m})$, JNK (SP600125, $20 \mu \mathrm{m})$, and p38 (SB203580, $20 \mu \mathrm{m})$ inhibitor resulted in amelioration of cocaine-

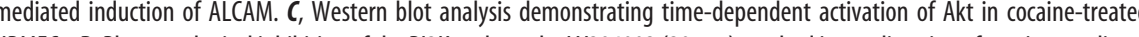
induction of ALCAM. All of the data are presented as mean \pm SD of four independent experiments. ${ }^{*} p<0.05,{ }^{* *} p<0.01$ versus control group; ${ }^{\# \#} p<0.01$ versus cocaine-treated group. Error bars indicate SEM.

firmed by transfecting cells with either the WT or DN Akt, followed by treatment with cocaine. Cocaine-mediated induction of ALCAM was attenuated by the DN-Akt, but not the WT-Akt construct (Fig. $8 \mathrm{E}$ ).

Cocaine-mediated activation of MAPK and Akt pathways involves upstream mediators such as $\sigma 1 \mathrm{R}, \mathrm{c}-\mathrm{Src}$, and PDGF- $\boldsymbol{\beta}$ R

Having determined that cocaine mediated translocation of the $\sigma 1 \mathrm{R}$ to the cell membrane and that subsequent activation of the c-Src, PDGF- $\beta$ R, and MAPKs pathways were critical processes involved in the induction of ALCAM, we next sought to link $\sigma 1 \mathrm{R}$ and PDGF- $\beta$ R activation with the signal transduction pathways. HBMECs pretreated with either the $\sigma 1 \mathrm{R}$ or PDGF- $\beta \mathrm{R}$ (antagonists and siRNAs), followed by treatment with cocaine, were assessed for activation of signaling pathways. Both $\sigma 1 \mathrm{R}$ and PDGF- $\beta$ R antagonists inhibited cocaine-mediated activation of MAPKs (ERK1/2, JNK, and p38) and Akt (Fig. 9A). In addition to the pharmacological approach, silencing using $\sigma 1 \mathrm{R}$ (Fig. 9B) and 
A
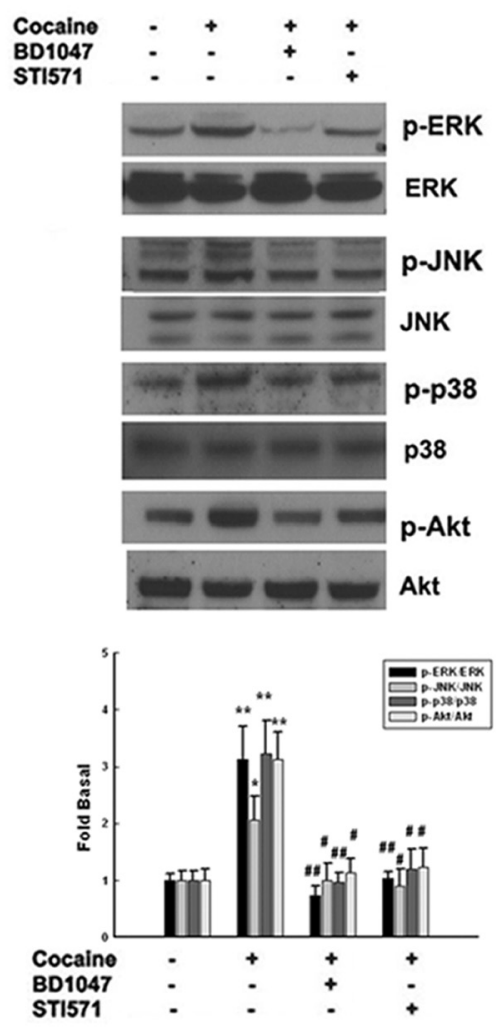

C
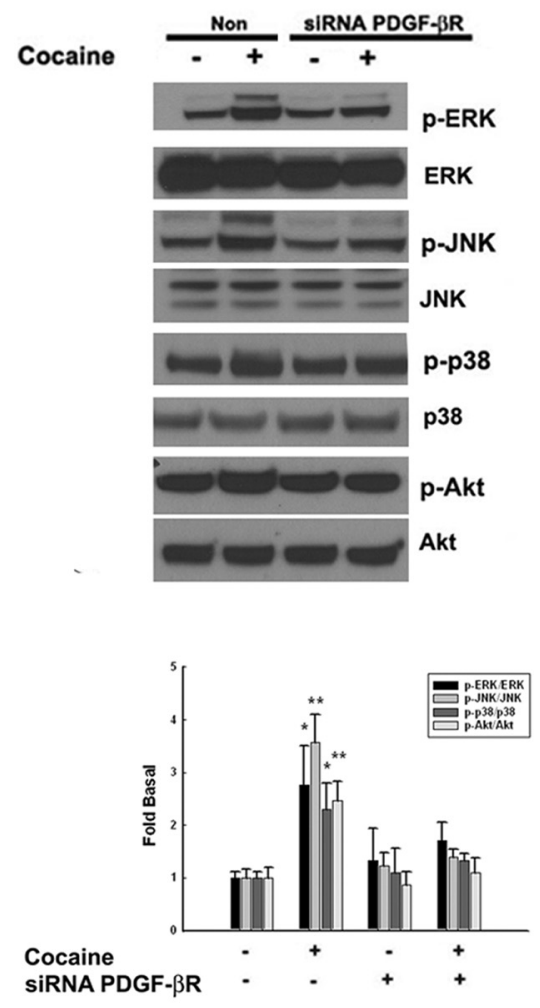

B
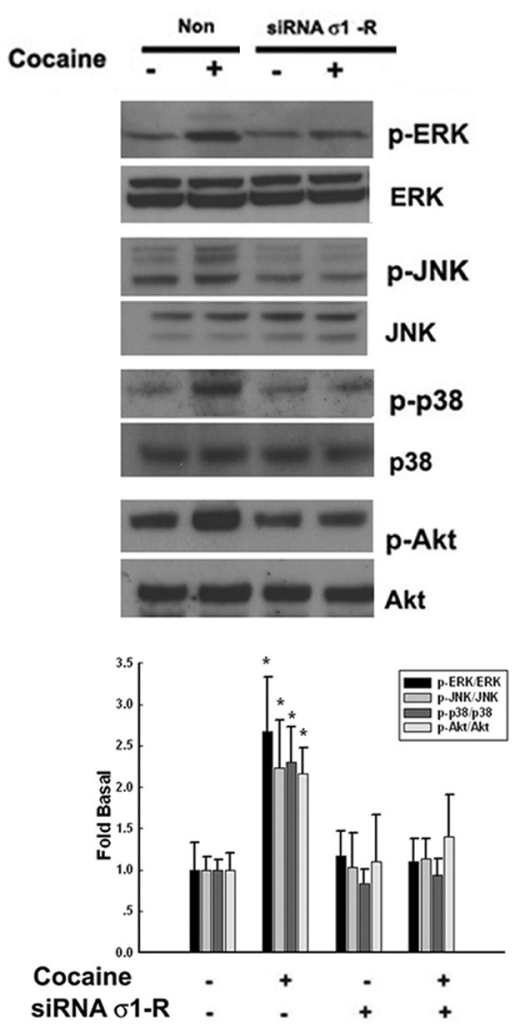

$\mathrm{D}$
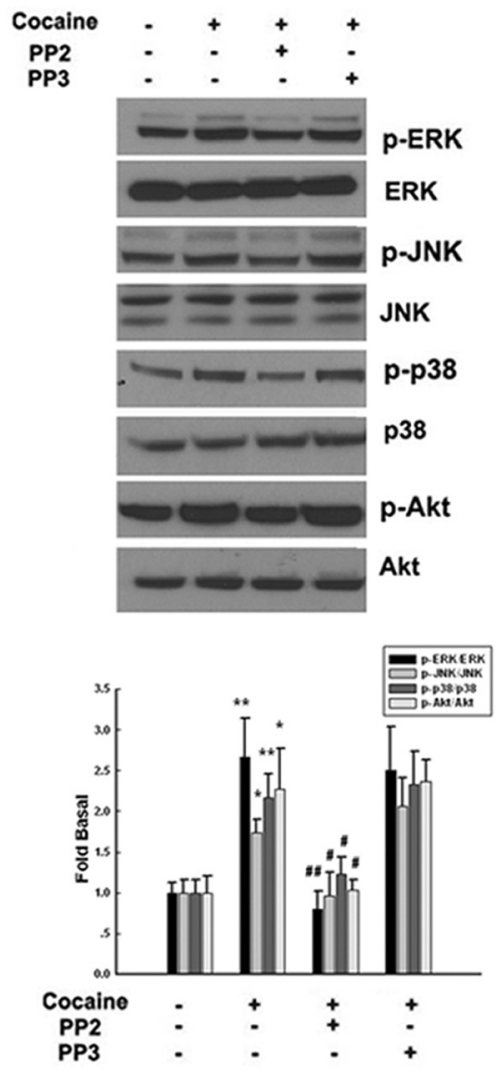

Figure 9. Involvement of $\sigma 1 \mathrm{R}$, Src kinase, and PDGF- $\beta$ R in the regulation of MAPKs and PI3K/Akt cell signaling pathways. Pretreatment of HBMECs with either BD1047 (20 $\mu \mathrm{m}) /$ STI-571 $(1 \mu \mathrm{M})(\boldsymbol{A}), \sigma 1 \mathrm{R}$ siRNA (B), PDGF- $\beta$ R siRNA (C), or c-Src inhibitor PP2 $(10 \mu \mathrm{M})(\boldsymbol{D})$ resulted in inhibition of cocaine-mediated phosphorylation of signaling pathways. Representative immunoblots and the densitometric analyses of $\mathrm{p}$-ERK/ERK, $\mathrm{p}$-JNK/JNK, p-p38/p38, and p-Akt/Akt from four separate experiments are presented. All of the data are indicated as mean $\pm S D$ of four independent experiments. ${ }^{*} p<0.05,{ }^{* *} p<0.01$ versus control group; $\# p<0.05$, ${ }^{\#} p<0.01$ versus cocaine-treated group. Error bars indicate SEM.

PDGF- $\beta$ R siRNAs (Fig. 9C) was also able to inhibit cocaine-mediated activation of these pathways. Similarly, we also found abrogation of cocaine-mediated activation of both MAPK and Akt pathways in cells pretreated with Src kinase inhibitor (Fig. 9D).

\section{Cocaine-mediated induction of ALCAM} involves NF- $\kappa \mathrm{B}$

\section{activation}

Members of the NF- $\kappa$ B family are considered to play essential roles in both cocaine- and PDGF- $\beta$ R-mediated signaling (Huang et al., 2003; F. S. Lin et al., 2005). Treatment of HBMECs with cocaine resulted in translocation of NF- $\kappa \mathrm{B}$ p65 into the nucleus (Fig. 10A). Pretreatment of cells with either $\mathrm{I} \kappa \mathrm{B}$ kinase- 2 inhibitor SC514 (Fig. 10B) or mutant NF- $\kappa \mathrm{B}$ adenovirus (Fig. 10C) abrogated cocaine-induced ALCAM expression, thereby underscoring the role of NF- $\kappa \mathrm{B}$ p65 in cocaine-mediated induction of ALCAM.

The next step was to examine whether there existed a link that could tie activation of $\sigma 1 \mathrm{R}$ and PDGF- $\beta \mathrm{R}$ with NF- $\kappa \mathrm{B}$ translocation. Both $\sigma 1 \mathrm{R}$ (Fig. 10D) and PDGF- $\beta$ R siRNAs (Fig. 10E) were able to inhibit cocaine-mediated activation of NF- $\kappa \mathrm{B}$. To further confirm the involvement of NF- $\kappa \mathrm{B}$, binding of NF- $\kappa \mathrm{B}$ to ALCAM promoter was explored using ChIP assays. These experiments revealed increased binding of NF- $\kappa \mathrm{B}$ to the ALCAM promoter in HBMECs treated with $\mathrm{CO}^{-}$ caine (Fig. $10 F, G)$.

Cocaine induced monocyte adhesion on HBMECs and monocyte transmigration across the in vitro $\mathrm{BBB}$ model

To identify the functional relevance of upregulated ALCAM, we examined the ability of cocaine-induced ALCAM to induce monocyte adhesion. Treatment of HBMECs with cocaine resulted in increase in both HIV-infected and uninfected monocyte adhesion (Fig. 11A,B). To confirm the role of ALCAM in this process, monocyte adhesion was evaluated in the presence of blocking antibodies. ALCAM antibody significantly restricted monocyte adhesion compared with the control (Fig. $11 C)$, suggesting thereby that ALCAM was critical for monocyte adhesion.

Roles of $\sigma 1 \mathrm{R}$ and PDGF- $\beta \mathrm{R}$ in this process were confirmed by pretreating cells with either the $\sigma 1 \mathrm{R}$ or PDGF- $\beta \mathrm{R}$ antagonist, both of which resulted in inhibition of monocyte adhesion (Fig. 11D). Similarly, a link between cocaine-mediated adhesion of monocytes and activation of c-Src with the signaling pathways was also established as 
evidenced by the fact that Src kinase inhibitor abolished cocaine-mediated monocyte adhesion (Fig. 11D). Inhibitors specific for MAPK, PI3K, and $\mathrm{I} \kappa \mathrm{B}$ kinase also blocked cocaine-induced monocyte adhesion (Fig. $11 E$ ), further supporting the notion that in HBMECs sequential activation of $\sigma 1 \mathrm{R} / \mathrm{Src} /$ PDGF- $\beta$ R/MAPK/PI3K pathways results in upregulation of ALCAM and monocyte adhesion.

Next, we examined the ability of cocaine to induce monocyte transmigration in an in vitro model of human BBB. Exposure of HBMECS to cocaine resulted in increased monocyte transmigration (Fig. $11 F)$. Pretreatment of HBMECs with anti-ALCAM antibody significantly restricted monocyte migration compared with the isotype control, thereby underpinning the role of ALCAM in transmigration of monocytes.

\section{Cocaine-mediated induction of ALCAM} in mouse models of systemic inflammation and T-cell deficiency To understand whether cocaine-mediated induction of ALCAM was dependent on systemic inflammation, two mouse models, (1) systemic inflammation model of LPS injection and (2) T-cell deficiency model using nude mice, were exposed to cocaine and examined for induction of ALCAM in the isolated brain microvessels. As shown in Figure $12 \mathrm{~A}$, administration of LPS resulted in induction of ALCAM expression compared with the control group without LPS exposure. This effect was potentiated in the presence of cocaine. Intriguingly, in T-cell-deficient mice, cocaine failed to induce ALCAM expression. These findings were also validated by confocal microscopy in sections of microvessels stained with ALCAM and caveolin-1 from the three groups of mice exposed to cocaine as shown in Figure $12 B$.

\section{Discussion}

Although antiviral therapies have had a profound impact on controlling systemic HIV-1 load leading to increased longevity in AIDS patients, the inability of some of these drugs to cross the $\mathrm{BBB}$ results in a slow and smoldering infection/cell activation in the CNS. As these patients continue to live longer, the brain becomes a sanctuary for virus-induced toxicity leading to increased prevalence of HAND. Adding fuel to this problem is the increased use of illicit drugs that is rapidly becoming a burgeoning problem in $\mathrm{HIV}^{+}$individuals (Goodkin et al., 1998). Intriguingly, abuse of the psychostimulant cocaine in these patients has been linked to increased HIV seroprevalence and disease progression (Goodkin et al., 1998). In cell culture studies, cocaine has been shown to disrupt BBB, thereby enhancing increased extravasation of infected/activated cells across the endothelium (Gan et al., 1999). Cocaine has also been shown to impair BBB by modulating tran-
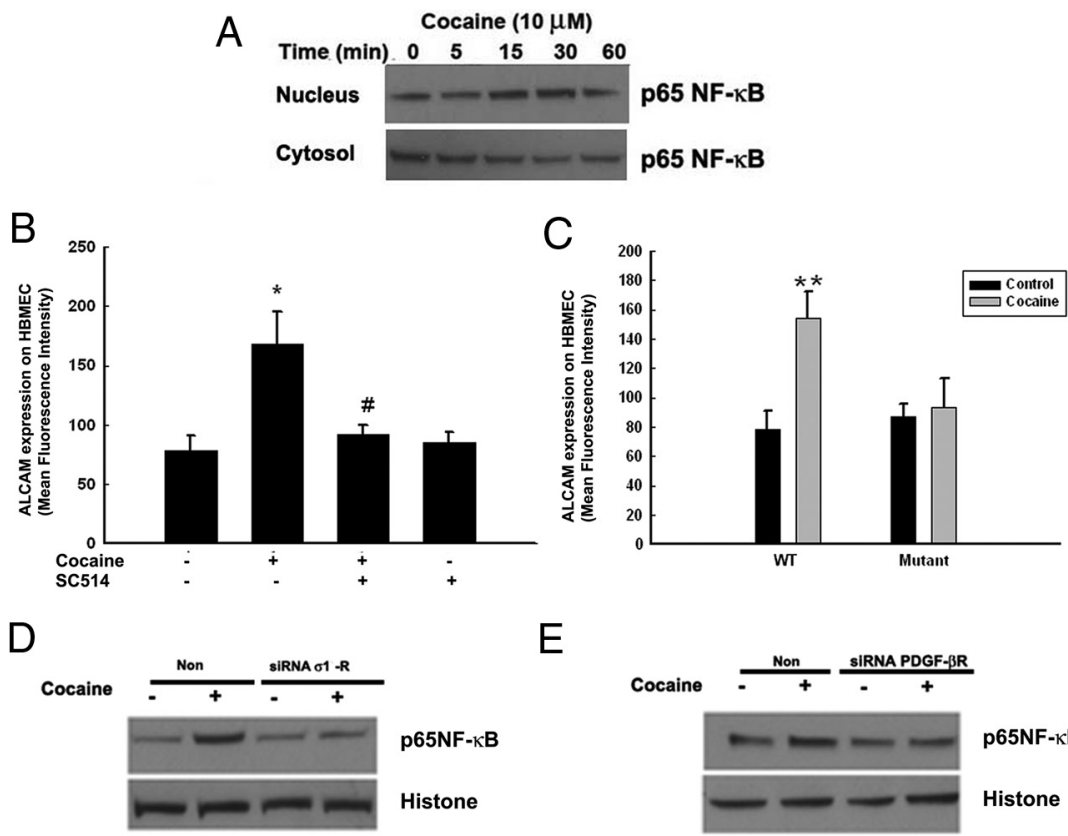

E
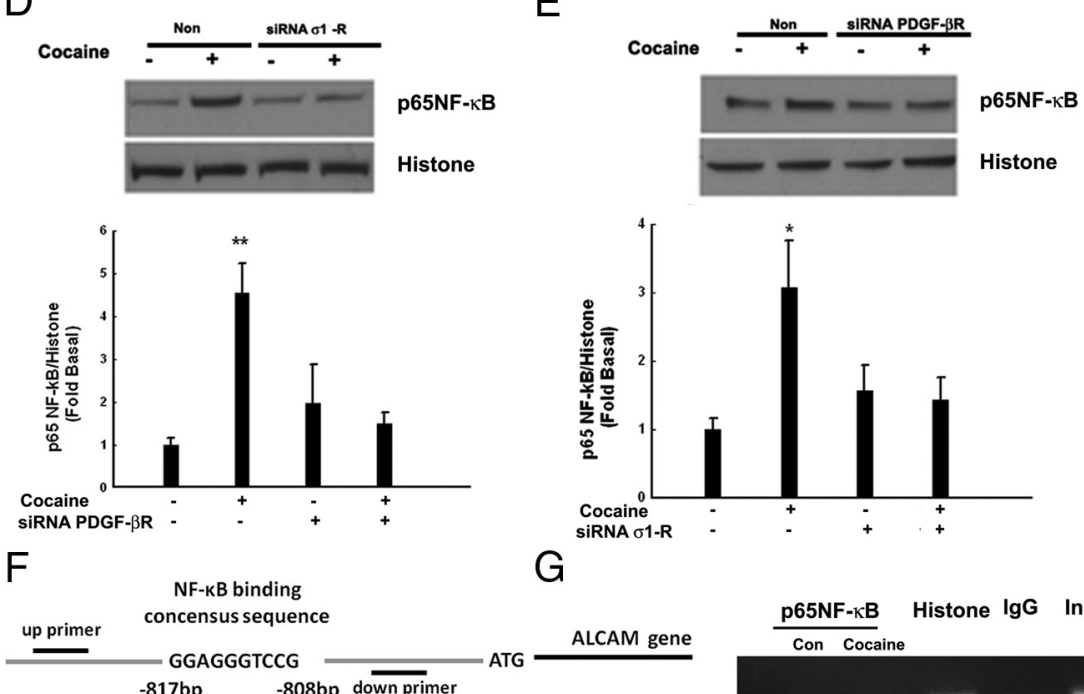

G

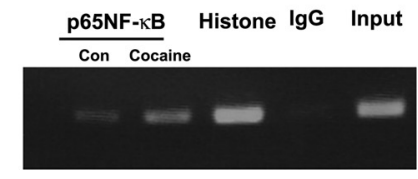

Figure 10. Cocaine-mediated induction of ALCAM expression involves NF- $\kappa$ B activation. $\boldsymbol{A}$, Western blot analysis demonstrating decrease in the cytosolic fraction. Flow-cytometric analysis indicating inhibition of cocaine-mediated induction of ALCAM in HBMECs: pretreated with the $I_{\kappa} B \alpha$ inhibitor, $S C 514(5 \mu \mathrm{m})(B)$, and overexpressing the mutant, but not the full-length p65/RelA NF- $\kappa B$ construct 列 for cocaine-mediated translocation of NF- $\kappa \mathrm{B}$ by Western blot analysis. Representative immunoblots and the densitometric analysis of tive of three independent experiments. All of the data are indicated as mean \pm SD of four independent experiments. ${ }^{*} p<0.05,{ }^{* *} p<$ 0.01 versus control group; ${ }^{\#} p<0.05$ versus cocaine-treated group. Error bars indicate SEM. scriptional regulation of key cellular functional genes (Fiala et al., 1998). Although cocaine has been shown to induce ICAM-1 and VCAM-1 expression, very few studies have actually explored direct effects of cocaine on the expression of ALCAM.

In the present study, we report cocaine-mediated transcriptional and translational induction of ALCAM in HBMECs. Our findings complement previous studies on the induction of ICAM-1 and VCAM-1 expression by cocaine (Gan et al., 1999). Triggering interaction of ALCAM-ALCAM or ALCAM-CD6 initiates monocyte transmigration through endothelial junctions both in the periphery (Masedunskas et al., 2006) and the CNS (Cayrol et al., 2008). Using human brain sections from $\mathrm{HIV}^{+}$/ cocaine drug abusers, we found that prominent upregulation of ALCAM in brain endothelium. ALCAM expression paralleled with macrophage recruitment. The study reported here provides 
A
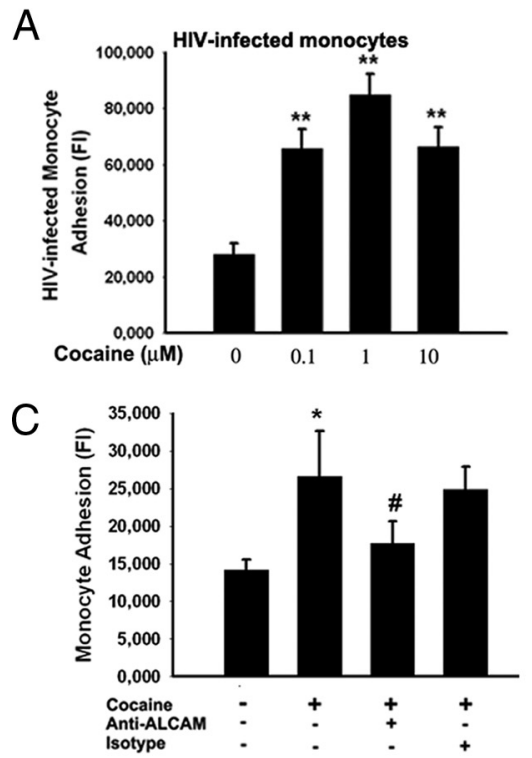

E

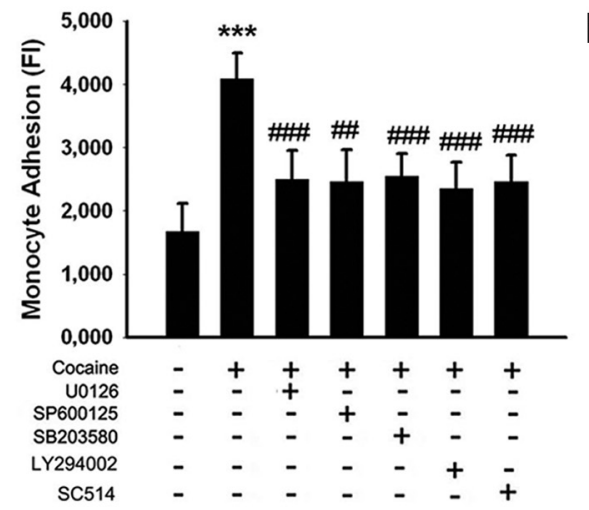

$\mathrm{B}$
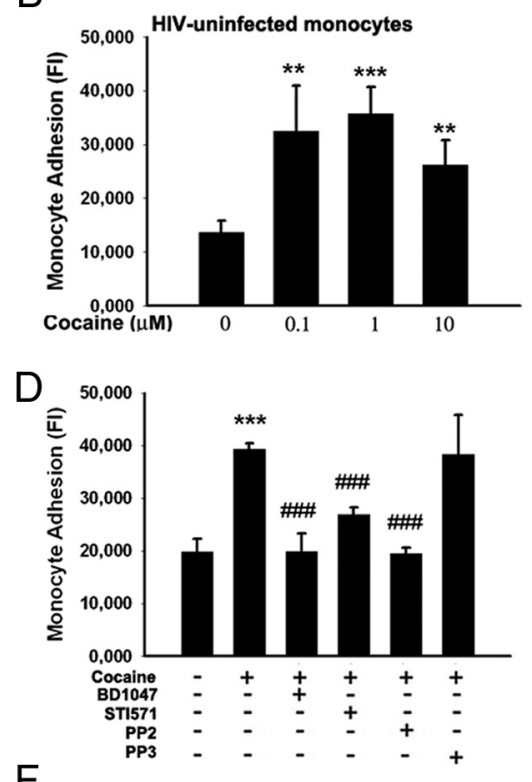

F

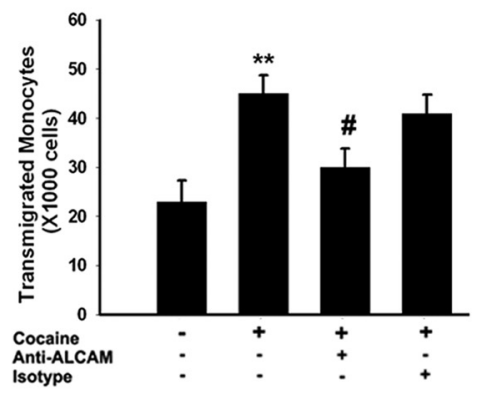

Figure 11. Cocaine-mediated induction of ACLAM enhances monocyte adhesion and transmigration in vitro. Exposure of HBMECS to varying concentrations of cocaine resulted in induction of HIV-infected $(\boldsymbol{A})$ and uninfected $(\boldsymbol{B})$ monoctye adhesion. $\boldsymbol{C}$, Cocaine-mediated induction of monoctye adhesion was ameliorated in HBMECs pretreated with the ALCAM-blocking antibody (1 $\mu \mathrm{g} / \mathrm{ml})$. D, Cocaine-mediated increase in monoctye adhesion was ameliorated in HBMECs pretreated with BD1047 $(20 \mu \mathrm{M})$, STI-571 $(1 \mu \mathrm{M})$, PP2 $(10 \mu \mathrm{M})$, but not PP3 $(1 \mu \mathrm{M})$. E, Cocaine-mediated increase in monoctye adhesion was ameliorated in HBMECS pretreated with MEK1/2 (U0126; $20 \mu \mathrm{M})$, JNK (SP600125; $20 \mu \mathrm{M})$, p38 (SB203580; $20 \mu \mathrm{M})$, PI3K (LY294002; $20 \mu \mathrm{M})$, or I $\kappa$ B inhibitor $(S C 514 ; 5 \mu \mathrm{M})$. All of the data are presented as mean $\pm S D$ of four individual experiments. ${ }^{* *} p<0.001$ versus control group; ${ }^{\# \# \# ~} p<0.001$ versus cocaine-treated group. $\boldsymbol{F}$, Cocaine-mediated increase in monoctye transmigration was ameliorated in HBMECs pretreated with the ALCAM-1-blocking antibody $(1 \mu \mathrm{g} / \mathrm{ml})$. All of the data are presented as mean \pm SD of four individual experiments. ${ }^{*} p<0.05,{ }^{* *} p<0.01,{ }^{* * *} p<0.001,{ }^{\#} p<0.05,{ }^{\# \# \#} p<0.001$ versus cocaine-treated group. Error bars indicate SEM.

first evidence of ALCAM upregulation in brain vasculature of $\mathrm{HIV}^{+}$drug abusers. Next, the functional significance of cocainemediated induction of ALCAM was examined in both the in vitro and in vivo models of monocyte adhesion and transmigration. Cocaine treatment of HBMECs resulted in increased monocyte adhesion and transmigration across an in vitro BBB model. Furthermore, both these effects were inhibited by treating cells with the neutralizing antibody specific for ALCAM. These findings were also validated in vivo wherein after cocaine injections there was increased expression of ALCAM resulting in increased transmigration of labeled monocytes into the brains. Furthermore, we also demonstrated that cocaine-mediated induction of ALCAM was dependent on systemic inflammation, as this effect of cocaine was not observed in the T-cell-deficient mouse model (Fig. 12). In concordance with cell culture studies, cocaine-mediated transmigration of monocytes was also abrogated in mice pretreated with the ALCAM neutralizing antibody. These findings are in

agreement with a recent study investigating the role of ALCAM in monocyte infiltration in MS and in EAE (Cayrol et al., 2008). It is likely that ALCAM expressed in response to cocaine binds either to the ALCAM or CD6 expressed on the bloodderived monocytes. Both the ALCAM ligands, CD6 and ALCAM, are expressed on monocytes isolated from the peripheral blood of healthy donors (Cayrol et al., 2008). In our study, cocaine treatment exerted no effect on the expression of ALCAM or CD6 in human monocytes (data not shown).

To delve deeper into the molecular mechanisms of cocaine-mediated induction of ALCAM, the role of $\sigma 1 \mathrm{R}$ was assessed. Cocaine-mediated induction of ALCAM involved $\sigma 1 \mathrm{R}$ activation since pretreatment of cells with $\sigma 1 \mathrm{R}$ antagonist abrogated induction of ALCAM. $\sigma 1 \mathrm{R}$ is known to translocate and remodel the plasma membrane after activation (Hayashi and Su, 2003, 2005; Monnet, 2005). Consistent with these findings, we demonstrated translocation of $\sigma 1 \mathrm{R}$ from the cytoplasm to the plasma membrane after cocaine treatment. Intriguingly, activation of $\sigma 1 \mathrm{R}$ with cocaine resulted in specific phosphorylation of PDGF- $\beta$ R. We demonstrated direct binding of $\sigma 1 \mathrm{R}$ with PDGF- $\beta R$ specifically at Tyr 751 . Plasma membranes thus serve as "platform or hubs" for coalescing the interaction of key signaling molecules triggered by cocaine. Furthermore, the interaction of $\sigma 1 \mathrm{R}$ with the PDGF- $\beta \mathrm{R}$ is in concordance with previous published reports suggesting $\sigma 1 \mathrm{R}$-mediated regulation of signaling of the tropic factors such as EGF (epidermal growth factor) receptor (Takebayashi et al., 2004).

The role of c-Src in cocaine-mediated induction of ALCAM expression reported here is consistent with previous reports implicating its involvement in TNF- $\alpha$ (tumor necrosis factor- $\alpha$ )/IL- $1 \beta$ (interleukin- $1 \beta$ )mediated induction of ICAM-1 expression (F. S. Lin et al., 2005; C. C. Lin et al., 2007). Another key point of our findings was that cocaine-mediated phosphorylation of PDGF- $\beta$ R was dependent on c-Src activation since inhibition of Src kinase significantly blocked cocaine-induced PDGF- $\beta$ R phosphorylation.

Intracellular signaling events such as MAPK kinases are known to be triggered by cocaine and during inflammation in the CNS (Yao et al., 2009b). Using both the pharmacological and genetic approaches, we examined the activation of MAPK kinase and PI3K/ Akt pathways in cocaine-mediated induction of ALCAM. These findings are consistent with the previous reports implicating the role of these signaling pathways in the induction of ICAM-1 (F. S. Lin et al., 2005; Xia et al., 2009). Cocaine-mediated induction of signaling was thus regulated by sequential upstream activation of $\sigma 1 \mathrm{R}, \mathrm{c}-\mathrm{Src}$, and PDGF- $\beta$ R.

Dissection of the downstream mediators of signaling pathways indicated phosphorylation and translocation of NF- $\kappa$ B. The 
requirement of $\mathrm{NF}-\kappa \mathrm{B}$ signaling in cell adhesion expression has been confirmed in previous studies (Ramudo et al., 2009; Sutcliffe et al., 2009). Additionally, MAPKs are also known to transduce their signals via activation and translocation of NF- $\kappa \mathrm{B}$ in various cells systems (Meucci et al., 2000). Consistent with these findings, we also demonstrated the role of MAPKs and p65/RelA nuclear translocation in cocaine-mediated induction of ALCAM expression.

In summary, our findings have chalked out a detailed molecular pathway of cocaine-mediated induction of ALCAM, involving activation and translocation of $\sigma 1 \mathrm{R}$, activation of $\mathrm{c}-\mathrm{Src}$, and subsequently of PDGF- $\beta$ R. It is likely that $\sigma 1 \mathrm{R}$ translocation brings together signaling molecules such as c-Src and PDGF- $\beta \mathrm{R}$ in close proximity for interaction/activation. Subsequently, the activation of MAPKs and PI3K/Akt pathways leads to translocation NF- $\kappa$ B into the nucleus, ultimately resulting in increased ALCAM. This, in turn, can lead to adhesion and recruitment of increased numbers of inflammatory cells onto the vessel endothelium. These findings have implications for HIV-1-infected cocaine abusers that have increased risk of stroke and CNSassociated neuroinflammation. Neutralizing ALCAM antibody can thus be considered as an adjunct therapeutic strategy for the treatment of cocaine addicts that are HIV-1 infected.

\section{References}

Bagasra O, Pomerantz RJ (1993) Human immunodeficiency virus type 1 replication in peripheral blood mononuclear cells in the presence of cocaine. $J$ Infect Dis 168:1157-1164.

Carlos TM, Harlan JM (1994) Leukocyteendothelial adhesion molecules. Blood 84:2068-2101.

Cayrol R, Wosik K, Berard JL, Dodelet-Devillers A, Ifergan I, Kebir H, Haqqani AS, Kreymborg K, Krug S, Moumdjian R, Bouthillier A, Becher B, Arbour N, David S, Stanimirovic D, Prat A (2008) Activated leukocyte cell adhesion molecule promotes leukocyte trafficking into the central nervous system. Nat Immunol 9:137-145.

Chaudhuri A, Yang B, Gendelman HE, Persidsky Y, Kanmogne GD (2008a) STAT1 signaling modulates HIV-1-induced inflammatory responses and leukocyte transmigration across the blood-brain barrier. Blood 111:2062-2072.

Chaudhuri A, Duan F, Morsey B, Persidsky Y, Kanmogne GD (2008b) HIV-1 activates proinflammatory and interferon-inducible genes in human brain microvascular endothelial cells: putative mechanisms of blood-brain barrier dysfunction. J Cereb Blood Flow Metab 28:697-711.

Eugenin EA, Osiecki K, Lopez L, Goldstein H, Calderon TM, Berman JW (2006) CCL2/monocyte chemoattractant protein-1 mediates enhanced transmigration of human immunodeficiency virus (HIV)-infected leukocytes across the blood-brain barrier: a potential mechanism of HIV-CNS invasion and NeuroAIDS. J Neurosci 26:1098-1106.
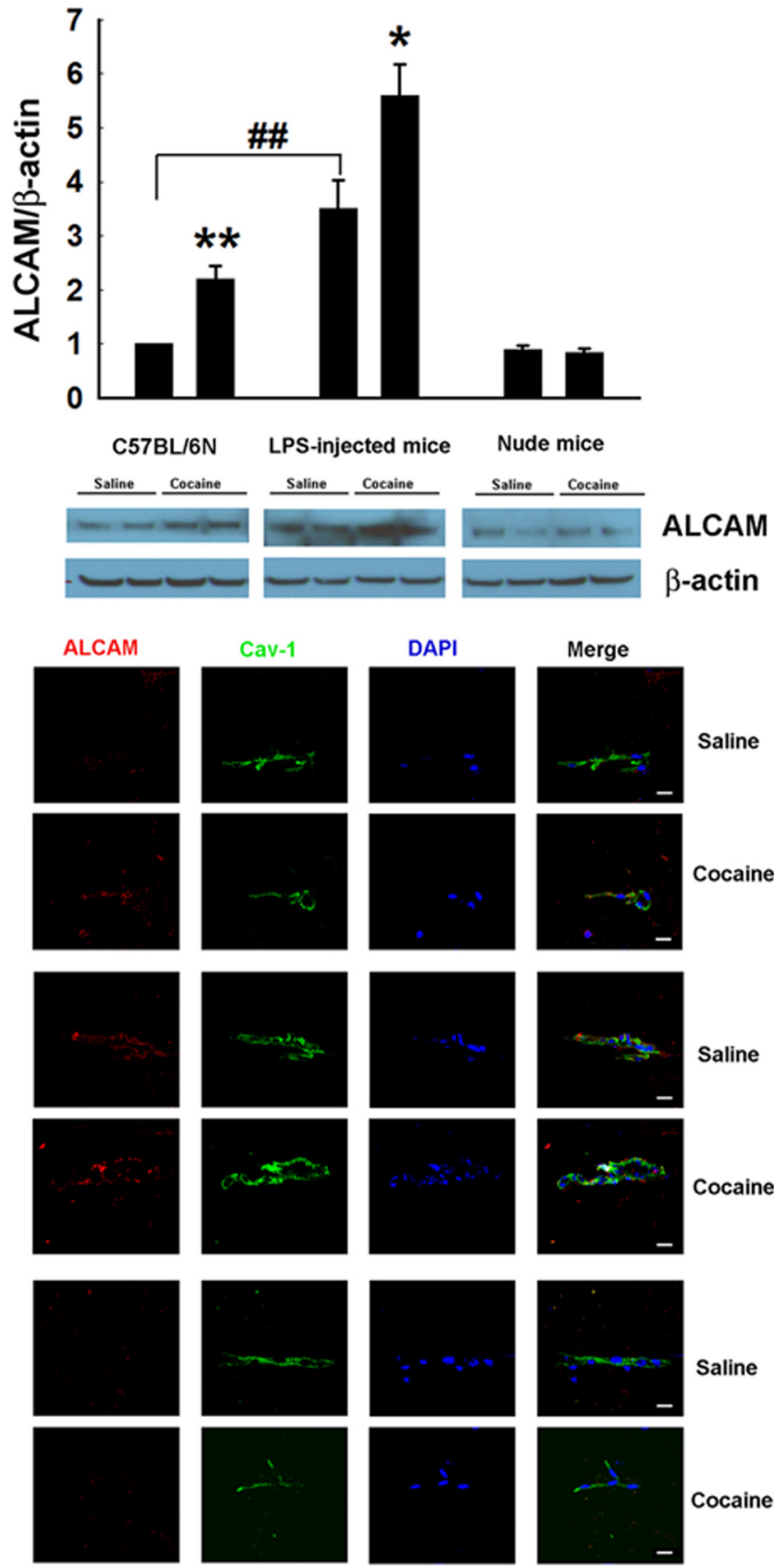

12. Effect of cocaine on induction of ALCAM expression in mouse models of systemic inflammation and T-cell deficiency. mation (LPS) and in T-cell-deficient mice as assessed by Western blot $(\boldsymbol{A})$ and immunostaining $(\boldsymbol{B})$. ALCAM, red; Cav-1, green nuclei, blue. $n=3$ per group. ${ }^{*} p<0.05$ versus saline group in LPS-injected mice; ${ }^{* *} p<0.01$ versus saline group in $C 57 \mathrm{BL} / 6 \mathrm{~N}$ mice; ${ }^{\# \#} p<0.01$ versus saline-treated C57BL/6N control group. Error bars indicate SEM.

Fiala M, Gan XH, Zhang L, House SD, Newton T, Graves MC, Shapshak P, Stins M, Kim KS, Witte M, Chang SL (1998) Cocaine enhances monocyte migration across the blood-brain barrier. Cocaine's connection to AIDS dementia and vasculitis? Adv Exp Med Biol 437:199-205.

Fiala M, Eshleman AJ, Cashman J, Lin J, Lossinsky AS, Suarez V, Yang W, Zhang J, Popik W, Singer E, Chiappelli F, Carro E, Weinand M, Witte M, Arthos J (2005) Cocaine increases human immunodeficiency virus type 1 neuroinvasion through remodeling brain microvascular endothelial cells. J Neurovirol 11:281-291.

Gan X, Zhang L, Berger O, Stins MF, Way D, Taub DD, Chang SL, Kim KS, House SD, Weinand M, Witte M, Graves MC, Fiala M (1999) Cocaine enhances brain endothelial adhesion molecules and leukocyte migration. Clin Immunol 91:68-76.

Gendelman HE, Orenstein JM, Martin MA, Ferrua C, Mitra R, Phipps T, 
Wahl LA, Lane HC, Fauci AS, Burke DS (1988) Efficient isolation and propagation of human immunodeficiency virus on recombinant colonystimulating factor 1-treated monocytes. J Exp Med 167:1428-1441.

Goodkin K, Shapshak P, Metsch LR, McCoy CB, Crandall KA, Kumar M, Fujimura RK, McCoy V, Zhang BT, Reyblat S, Xin KQ, Kumar AM (1998) Cocaine abuse and HIV-1 infection: epidemiology and neuropathogenesis. J Neuroimmunol 83:88-101.

Hayashi T, Su TP (2003) Sigma-1 receptors (sigma(1) binding sites) form raft-like microdomains and target lipid droplets on the endoplasmic reticulum: roles in endoplasmic reticulum lipid compartmentalization and export. J Pharmacol Exp Ther 306:718-725.

Hayashi T, Su TP (2005) The potential role of sigma-1 receptors in lipid transport and lipid raft reconstitution in the brain: implication for drug abuse. Life Sci 77:1612-1624.

Huang W, Rha GB, Chen L, Seelbach MJ, Zhang B, András IE, Bruemmer D, Hennig B, Toborek M (2010) Inhibition of telomerase activity alters tight junction protein expression and induces transendothelial migration of HIV1-infected cells. Am J Physiol Heart Circ Physiol 298:H1136-H1145.

Huang WC, Chen JJ, Chen CC (2003) c-Src-dependent tyrosine phosphorylation of IKKbeta is involved in tumor necrosis factor-alpha-induced intercellular adhesion molecule-1 expression. J Biol Chem 278:9944-9952.

Kanmogne GD, Schall K, Leibhart J, Knipe B, Gendelman HE, Persidsky Y (2007) HIV-1 gp120 compromises blood-brain barrier integrity and enhances monocyte migration across blood-brain barrier: implication for viral neuropathogenesis. J Cereb Blood Flow Metab 27:123-134.

Kaul M, Ma Q, Medders KE, Desai MK, Lipton SA (2007) HIV-1 coreceptors CCR5 and CXCR4 both mediate neuronal cell death but CCR5 paradoxically can also contribute to protection. Cell Death Differ 14:296-305.

Koutsilieri E, Götz ME, Sopper S, Sauer U, Demuth M, ter Meulen V, Riederer P (1997) Regulation of glutathione and cell toxicity following exposure to neurotropic substances and human immunodeficiency virus- 1 in vitro. J Neurovirol 3:342-349.

Lin CC, Lee CW, Chu TH, Cheng CY, Luo SF, Hsiao LD, Yang CM (2007) Transactivation of Src, PDGF receptor, and Akt is involved in IL-1betainduced ICAM-1 expression in A549 cells. J Cell Physiol 211:771-780.

Lin FS, Lin CC, Chien CS, Luo SF, Yang CM (2005) Involvement of p42/p44 MAPK, JNK, and NF-kappaB in IL-1beta-induced ICAM-1 expression in human pulmonary epithelial cells. J Cell Physiol 202:464-473.

Masedunskas A, King JA, Tan F, Cochran R, Stevens T, Sviridov D, OforiAcquah SF (2006) Activated leukocyte cell adhesion molecule is a component of the endothelial junction involved in transendothelial monocyte migration. FEBS Lett 580:2637-2645.

Meucci O, Fatatis A, Simen AA, Miller RJ (2000) Expression of CX3CR1 chemokine receptors on neurons and their role in neuronal survival. Proc Natl Acad Sci U S A 97:8075-8080.
Monnet FP (2005) Sigma-1 receptor as regulator of neuronal intracellular $\mathrm{Ca}^{2+}$ : clinical and therapeutic relevance. Biol Cell 97:873-883.

Nummer D, Suri-Payer E, Schmitz-Winnenthal H, Bonertz A, Galindo L, Antolovich D, Koch M, Büchler M, Weitz J, Schirrmacher V, Beckhove P (2007) Role of tumor endothelium in CD4 + CD25+ regulatory T cell infiltration of human pancreatic carcinoma. J Natl Cancer Inst 99:1188-1199.

Ramirez SH, Heilman D, Morsey B, Potula R, Haorah J, Persidsky Y (2008) Activation of peroxisome proliferator-activated receptor gamma (PPARgamma) suppresses Rho GTPases in human brain microvascular endothelial cells and inhibits adhesion and transendothelial migration of HIV-1 infected monocytes. J Immunol 180:1854-1865.

Ramirez SH, Fan S, Dykstra H, Reichenbach N, Del Valle L, Potula R, Phipps RP, Maggirwar SB, Persidsky Y (2010) Dyad of CD40/CD40 ligand fosters neuroinflammation at the blood-brain barrier and is regulated via JNK signaling: implications for HIV-1 encephalitis. J Neurosci 30:9454-9464.

Ramudo L, Yubero S, Manso MA, Vicente S, De Dios I (2009) Signal transduction of MCP-1 expression induced by pancreatitis-associated ascitic fluid in pancreatic acinar cells. J Cell Mol Med 13:1314-1320.

Schilling M, Strecker JK, Ringelstein EB, Kiefer R, Schäbitz WR (2009) Turn-over of meningeal and perivascular macrophages in the brain of MCP-1-, CCR-2- or double knockout mice. Exp Neurol 219:583-585.

Sutcliffe AM, Clarke DL, Bradbury DA, Corbett LM, Patel JA, Knox AJ (2009) Transcriptional regulation of monocyte chemotactic protein-1 release by endothelin-1 in human airway smooth muscle cells involves NF-kappaB and AP-1. Br J Pharmacol 157:436-450.

Swart GW (2002) Activated leukocyte cell adhesion molecule (CD166/ALCAM): developmental and mechanistic aspects of cell clustering and cell migration. Eur J Cell Biol 81:313-321.

Takebayashi M, Hayashi T, Su TP (2004) Sigma-1 receptors potentiate epidermal growth factor signaling towards neuritogenesis in PC12 cells: potential relation to lipid raft reconstitution. Synapse 53:90-103.

Xia M, Ling W, Zhu H, Ma J, Wang Q, Hou M, Tang Z, Guo H, Liu C, Ye Q (2009) Anthocyanin attenuates CD40-mediated endothelial cell activation and apoptosis by inhibiting CD40-induced MAPK activation. Atherosclerosis 202:41-47.

Yao H, Peng F, Dhillon N, Callen S, Bokhari S, Stehno-Bittel L, Ahmad SO, Wang JQ, Buch S (2009a) Involvement of TRPC channels in CCL2mediated neuroprotection against tat toxicity. J Neurosci 29:1657-1669.

Yao H, Allen JE, Zhu X, Callen S, Buch S (2009b) Cocaine and human immunodeficiency virus type 1 gp120 mediate neurotoxicity through overlapping signaling pathways. J Neurovirol 15:164-175.

Yao H, Yang Y, Kim KJ, Bethel-Brown C, Gong N, Funa K, Gendelman HE, Su TP, Wang JQ, Buch S (2010) Molecular mechanisms involving sigma receptor-mediated induction of MCP-1: implication for increased monocyte transmigration. Blood 115:4951-4962. 